\title{
Analysis of Seasonal Daytime Urban Thermal Environment Dynamics in a Tropical Coastal City Based on the Spatiotemporal Fusion Model
}

\author{
Yuan Yao $\mathbb{D}^{1,2}$ Yiling Lu, ${ }^{1}$ Fang Zhang $\mathbb{D}^{3},{ }^{3}$ Lulu Liu $\mathbb{D}^{1,2}$ and Min Liao ${ }^{1}$ \\ ${ }^{1}$ School of Architecture and Civil Engineering, Chengdu University, Chengdu 610106, China \\ ${ }^{2}$ Key Laboratory of Pattern Recognition and Intelligent Information Processing, \\ Institutions of Higher Education of Sichuan Province, Chengdu University, Chengdu 610106, China \\ ${ }^{3}$ College of Resources and Environmental Sciences, Xinjiang University, Urumqi 830046, China \\ Correspondence should be addressed to Fang Zhang; zhangfang@xju.edu.cn
}

Received 14 October 2019; Revised 3 April 2020; Accepted 7 November 2020; Published 23 November 2020

Academic Editor: Stefania Bonafoni

Copyright (c) 2020 Yuan Yao et al. This is an open access article distributed under the Creative Commons Attribution License, which permits unrestricted use, distribution, and reproduction in any medium, provided the original work is properly cited.

\begin{abstract}
This study investigated the seasonal variations of daytime urban thermal environment (UTE) based on land surface temperature (LST) in Shenzhen of 2015. The spatial and temporal adaptive reflectance fusion model (STARFM) was used for retrieving seasonal daytime LST at high spatiotemporal resolution by combining MODIS and HJ-1B LST data. Next, the relationship between the land cover and daytime in each season was examined. Finally, daytime LST patterns were classified, and the effects of seasonal variations of high-grade daytime LSTs were analyzed with landscape metrics. The results showed that (1) the STARFM is capable of generating seasonal daytime LST data at high spatiotemporal resolution. (2) Daytime LSTs were generally higher in the western parts of Shenzhen in spring and summer. (3) Daytime LST in each land cover type showed an increasing trend form winter to summer and decreased from summer to autumn. The highest and lowest daytime LSTs in each season were observed in ISAs and water bodies. (4) Landscape metrics provided a quantitative method for describing seasonal variations in daytime LSTs, and it was found that seasons influenced the intensity and extent of daytime LSTs in Shenzhen. These findings may be helpful for urban planners developing regional urban strategies to improve daytime urban thermal comfort conditions.
\end{abstract}

\section{Introduction}

More than $54 \%$ of the world's population now lives in urban areas according to the 2014 revision of the World Urbanization Prospects of the United Nations [1]. This proportion will likely grow in the future, particularly in developing countries [2]. Thus, urban areas are continuously growing, and a large amount of natural vegetation coverage converted to various impervious surfaces areas (ISAs) will likely result in a series of human living environmental and ecological issues [3]. The urban thermal environment (UTE) is an important part of the urban ecoenvironment, which could be altered by urbanization and industrialization [4]. The UTE could potentially be changed by air pollution, industrial waste heat, land use/cover change (LUCC), and other factors [5]. With increasing trends of climate warming in urban areas over the last 50 years, higher temperatures not only lead to a series of changes in the urban environment, such as accelerated formation of polluted air and change in the energy budget at the ground surface, but also generate a great amount of anthropogenic waste heat, contributing to global warming [6]. One consequence of UTE change due to urbanization is the urban heat island (UHI). An UHI refers to the phenomenon by which most of the urban areas worldwide have significantly higher temperatures when compared with their rural and suburban counterparts [7]. UHIs have caused adverse impacts on the daily life of city residents, such as increase in urban thermal discomfort [8], increase in energy consumption [9], and dispersing air pollution [10]. Recently, in order to fight the UHI and its detrimental consequences, various strategies have been developed, such as using permeable and reflective pavements 
[11] and addressing the green building to solve the problems of energy consumption and carbon emissions [12], and a consortium of strategies and techniques, including cool materials [13], water bodies [14], and urban greenery [15], has been used for UHI mitigation.

Land surface temperature (LST) is the most important indicator and key step to studying the UTE. Among the sources of optical remotely sensed data, Landsat series are most widely used for retrieving LSTs because of their long time span, global coverage, and high spatial resolution. For example, Landsat TM/ETM+/8 are designed with a Thermal Infrared Sensor (TIR) at high spatial resolutions of $120 \mathrm{~m}$, $60 \mathrm{~m}$, and $100 \mathrm{~m}$. Many algorithms have been proposed to retrieve LST from Landsat series, e.g., single-channel methods [16], monowindow algorithm [17], and the radiative transfer equation [18]. A comprehensive assessment of different LST retrieval methods over rural areas can be found in Sekertekin and Bonafoni [19]; they found that all methods provided satisfying results, but monowindow algorithm has a better performance. Yu et al. [20] compared three different approaches for LST inversion from Landsat 8, and results show that the radiative transfer equation-based method has the highest accuracy. However, many of the Landsat series are hindered by the presence of cloud cover, especially in the tropics [21]. It is difficult to acquire cloudless images for studying seasonal variations of daytime UTE in tropical coastal cities owing to their relatively not very high temporal resolution of 16 days. This is a serious issue in a sense that genuine daytime UTE studies need multiple scenes of Landsat images for the same season in different time periods. Although high temporal resolution (1 days) of Moderateresolution Imaging Spectroradiometer (MODIS) images have a greater possibility to acquire cloudless images, the generalized split-window algorithm [22] which generates the MOD11A LST product at $1 \mathrm{~km}$ resolution may not able to monitor the detailed urban LST distribution in a single city area, which, to some extent, make them more applicable to regional and global scales [23]. Therefore, there is so far no single satellite data that can provide high spatiotemporal resolution images. There is a trade-off between spatial resolution and a repeated observation cycle in current satellite remote sensing systems, which limited the application of TIR remote sensing data in UTE studies. At present, spatiotemporal fusion is a relatively new concept resolving this problem. In the past decade, many spatiotemporal fusion methods have been proposed to generate high spatial and temporal resolution LST data [24-26]. One of the most widely used spatiotemporal fusion technology has been the spatial and temporal adaptive reflectance fusion model (STARFM) [27]. Liu and Weng [28] applied the STARFM to blend MODIS and ASTER LST data and predict ASTER-like LST images for Los Angeles, the LST residual less than $1^{\circ} \mathrm{C}$ for all images. Huang et al. [29] improved the STARFM to generate high-spatiotemporal resolution LST data by combing MODIS and Landsat LST data for UTE monitoring. On September 6, 2008, China launched the HuanJing-1B (HJ-1B) satellites; the spatial resolution of the HuanJing-1B thermal infrared sensor band-4 (IRS4) is $300 \mathrm{~m}$, and the returning cycle is 4 days, increasing the probability of acquiring cloud-free images for a given time, especially in the tropical coastal cities. Thus, the HJ-1B satellites can be a good data source for research on the effects of the daytime UTE in different seasons.

In Shenzhen, a major international tropical costal city in China that has experienced rapid economic development, the daytime UTE is often affected by rainy and cloud weather. In this study, in order to assess the seasonal variations of the daytime UTE in Shenzhen, we used the STARFM framework to produce seasonal high-spatiotemporal resolution daytime LST data by combining MODIS and HJ-1B LST data. Our objective was to (1) generate synthetic high-spatiotemporal resolution LST data covering the study area for seasonal daytime UHE monitoring, (2) examine the seasonal variations of the daytime LST to different land cover types, and (3) assess the effects of seasonal variations of high-grade daytime LST using landscape metrics.

\section{Materials and Methods}

2.1. Study Area. The city of Shenzhen, the selected study area, lies in the south of Guangdong Province. This first Special Economic Zone in China, along with the Hong Kong Special Administrative Region to the south, stands between the Pearl River Estuary to the west and Daya Bay to the east, at $22^{\circ} 26^{\prime}-22^{\circ} 51^{\prime}$ and $113^{\circ} 45^{\prime}-114^{\circ} 37^{\prime}$ (Figure 1). The city covers an area of $1997.30 \mathrm{~km}^{2}$. The mean annual temperature of Shenzhen is $23.0^{\circ} \mathrm{C}$, with mean maximum and minimum temperatures of $28.9^{\circ} \mathrm{C}$ in July and $15.4^{\circ} \mathrm{C}$ in January. The southern subtropical monsoon climate brings a mean annual rainfall of $1933.33 \mathrm{~mm}$. The rainy season in Shenzhen extends from April to September. This long and narrow territory has a lower elevation in the northwest and higher in the southeast.

We chose Shenzhen as a case study because since 1979, the region has been transformed from an unknown small town to an international modernized metropolis comprising ten administrative districts that have experienced rapid economic development and urban expansion. The gross domestic product (GDP) was 1,750299 trillion RMB, and the total residing population was estimated at $10,778,900$ in 2015. The rapid overpopulation and industrialization have caused the natural land cover types to be extensively converted into man-made land cover types in such a way that the characteristics of open water and forestland have been increasingly altered to becoming an impervious surface area. This change caused the urban surface to experience wide thermal and environmental variation, which affects the spatiotemporal variability of the daytime UTE.

2.2. LST Retrieval from $\mathrm{HJ}-1 \mathrm{~B}$. The $\mathrm{HJ}-1 \mathrm{~B}$ satellite carries two charge-coupled devices including one thermal infrared sensor (IRS) and two charged coupled device (CCD) cameras; the sensor parameters are listed in Table 1 [30]. The data are characterized by a high revisiting frequency over China and stable radiation properties, which make the data suitable for daytime UTE monitoring. 


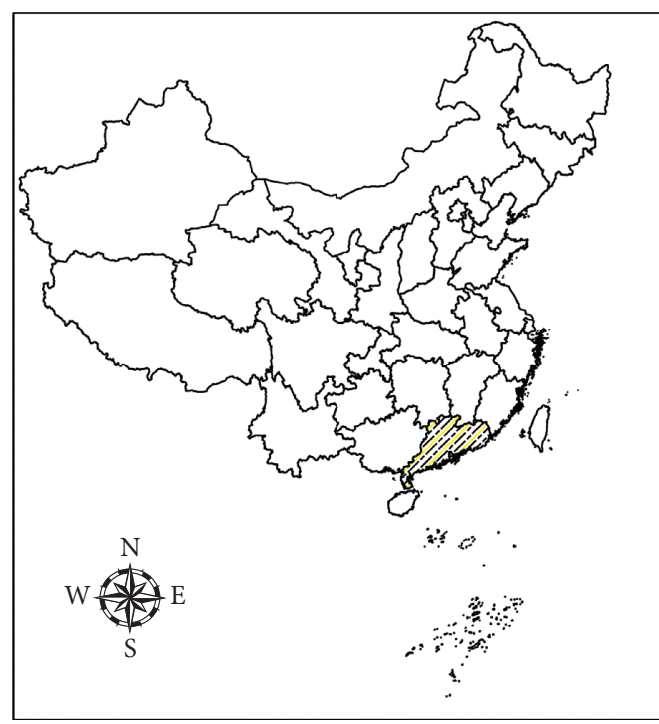

(a)

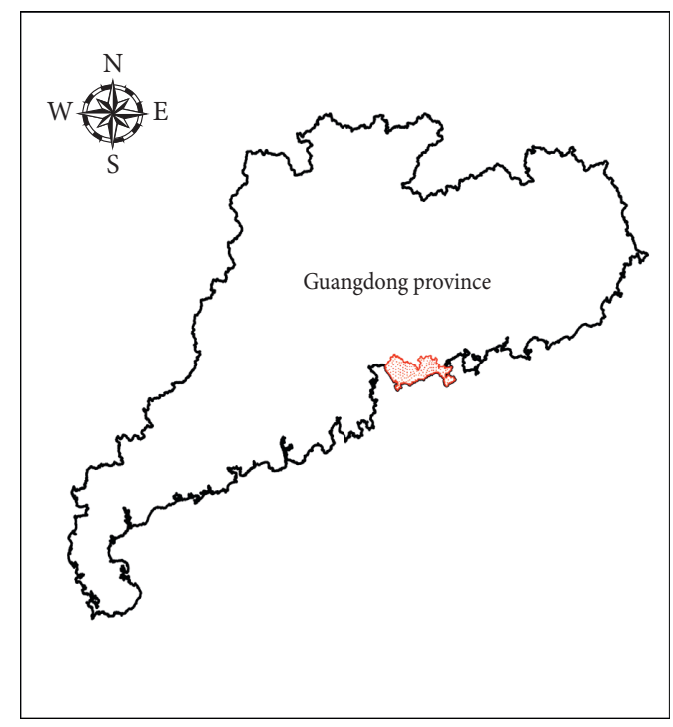

(b)

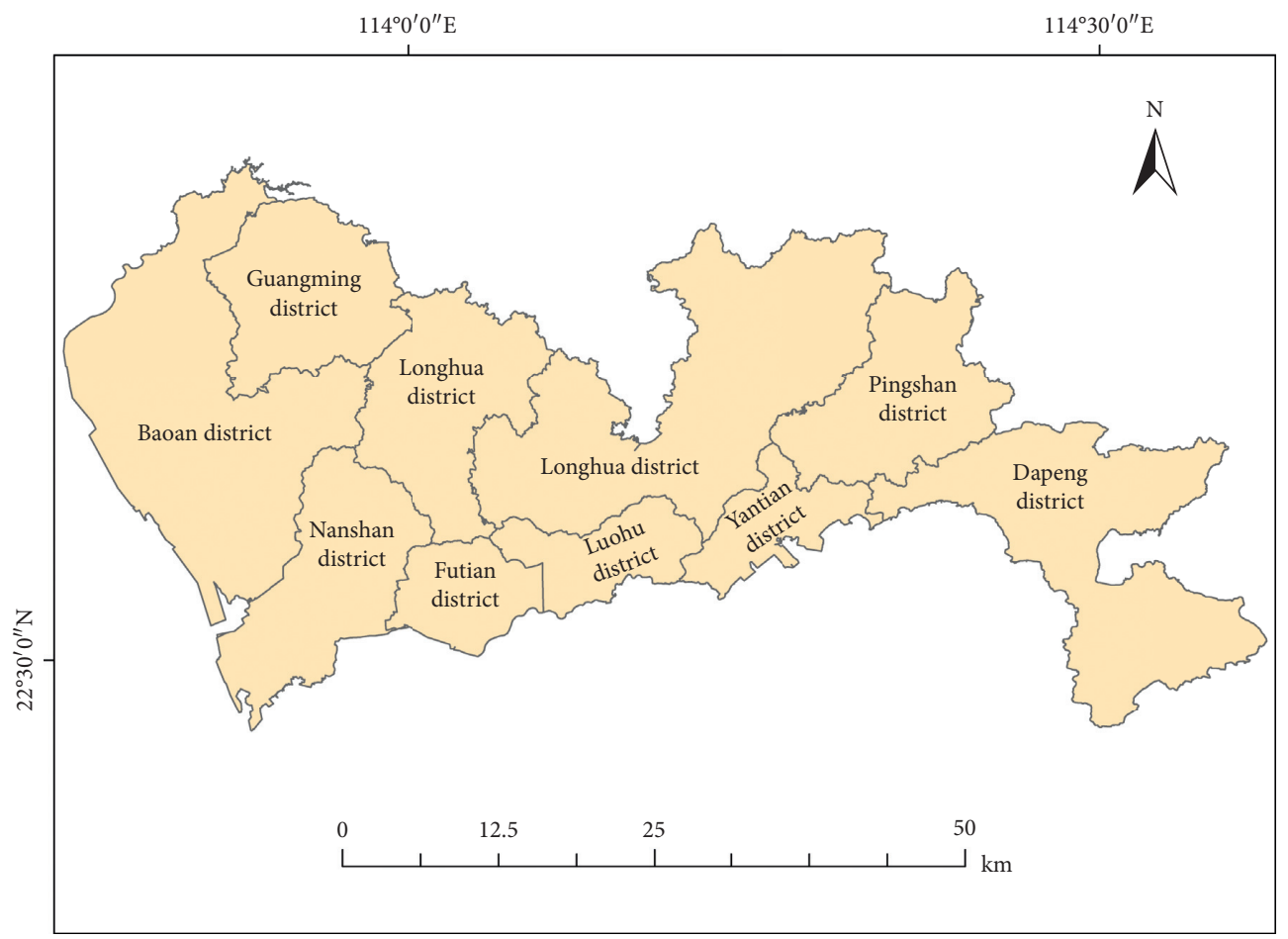

(c)

Figure 1: Location of the study area: (a) location of Guangdong Province within China; (b) location of the Shenzhen within Guangdong Province; and (c) districts of Shenzhen within the study area.

In this study, the seasonal division was made based on an announcement made by the Meteorological Bureau of Shenzhen Municipality, which used a 5 Day Running Mean Temperature method based on meteorological data (1980-2010) of Shenzhen collected in 2015. The announcement designated January 13 to February 6 to represent winter, February 7 to April 21 for spring, April 22 to November 3 for summer, and November 4 to January 12 of the next year for fall [31]. Compared to HJ-1B, Landsat data are invariably contaminated by clouds constraining the utilization for seasonal variations of daytime UTE monitoring. Taking Shenzhen as an example, two different date scenes of Landsat data should be involved to cover the whole city. There are only 4 available Landsat images without cloud cover in 2015. Those are images acquired on January 3, January 19, August 8 , and October 18, respectively, which makes it practically impossible to assess the seasonal variations. Therefore, in order to investigate the seasonal variations of daytime UTE in Shenzhen, four high-quality and cloudless HJ-1B CCD and IRS images in 2015, acquired from the China Centre 
TABLE 1: Temperature and wildlife count in the three areas covered by the study.

\begin{tabular}{|c|c|c|c|c|c|c|c|c|}
\hline \multirow{2}{*}{$\begin{array}{l}\text { Parameters } \\
\text { Band }\end{array}$} & \multicolumn{4}{|c|}{$\mathrm{CCD} 1 / \mathrm{CCD} 2$} & \multicolumn{4}{|c|}{ IRS } \\
\hline & $\begin{array}{c}1 \\
\text { Blue }\end{array}$ & $\begin{array}{c}2 \\
\text { Green }\end{array}$ & $\begin{array}{c}3 \\
\text { Red }\end{array}$ & $\begin{array}{c}4 \\
\text { Infrared }\end{array}$ & $\begin{array}{c}5 \\
\text { NIR }\end{array}$ & $\begin{array}{c}6 \\
\text { SWIR }\end{array}$ & $\begin{array}{c}7 \\
\text { MIR }\end{array}$ & $\begin{array}{c}8 \\
\text { TIR }\end{array}$ \\
\hline Spatial resolution & \multicolumn{4}{|c|}{$30 \mathrm{~m}$} & \multirow{2}{*}{\multicolumn{3}{|c|}{$\begin{array}{c}150 \mathrm{~m} \\
0.75-3.90\end{array}$}} & $300 \mathrm{~m}$ \\
\hline Spectral range $(\mu \mathrm{m})$ & \multicolumn{4}{|c|}{$0.43-0.90$} & & & & $10.5-12.5$ \\
\hline Revisit cycle & \multicolumn{4}{|c|}{2 days } & \multicolumn{4}{|c|}{4 days } \\
\hline Amplitude width & & & & & \multicolumn{4}{|c|}{$720 \mathrm{~km}$} \\
\hline
\end{tabular}

Note. CCD, charged coupled device; IRS, infrared camera sensor; MIR, middle infrared; NIR, near infrared; SWIR, short-wavelength infrared; TIR, thermal infrared.

Resources Satellite Data and Application (http://www.cresda. com/CN/), were selected from 4844 available images during 2008-2016. The selected HJ-1B CCD and IRS images were captured on January 16, April 14, October 18, and December 18,2015 , to represent winter, spring, summer, and autumn, respectively (Table 2). The four selected images were deemed usable and were selected for predicting high-spatiotemporal resolution LST data in this study, and they were all acquired at approximately 11:05 a.m. local time under uniform atmospheric conditions favorable for daytime UTE studies such as during sunny and windless weather.

The HJ-1B images used here are level- 2 output products that have been corrected for geometrical distortions before they were delivered to us. All images were preprocessed in steps including (1) geometric correction: selecting calibrated Landsat 8 images in the study area for geometric correction; the error met the geometry correction requirement that was controlled within 0.5 pixels. (2) Radiometric calibration: using the calibration coefficients [32] to convert the digital number $(\mathrm{DN})$ value of the raw $\mathrm{HJ}-1 \mathrm{~B}$ image to the satellite radiance image [33]. (3) Atmospheric correction: in this paper, the ENVI-FLAASH module was used for atmospheric correction. Correcting each HJ-1B CCD image after radiometric calibration is important because this can eliminate the influence of atmospheric and light factors on ground reflections. In this study, we retrieved LST data from the thermal band IRS4 of HJ-1B imagery using the monowindow algorithm. For a more detailed description of the monowindow algorithm, please refer to the work of Qin et al. [17].

2.3. Preprocessing of MODIS LST Images. Daily daytime (MOD11A1) and 8 day average (MOD11A2) $1 \mathrm{~km}$ spatial resolution MODIS LST data (Table 3) that overpass $10.30 \mathrm{am}$ of local time covering the study area in 2015 were acquired from NASA's Earth Observing System Data and Information System (https://earthdata.nasa.gov). The accuracy of these data has been verified as high in global cities [34, 35]. We used the US National Aeronautics and Space Administration's Modis Reprojection Tool to reproject the same coordinate system as $\mathrm{HJ}-1 \mathrm{~B}$ and make geometric corrections and calculated the LST using the following equation [36]:

$$
T_{S}=\mathrm{DN} \times 0.02-273.15 \text {, }
$$

where $T_{S}$ is the value of the LST, DN is the digital number of the MODIS LST data, 0.02 is the ratio of radiation scaling, and 273.15 is the difference between Kelvin (K) and Celsius degree temperatures $\left({ }^{\circ} \mathrm{C}\right)$.

2.4. STARFM. The STARFM was originally designed by Gao et al. [27] to predict daily surface reflectance using Landsat and MODIS images. The premise of the STARFM is that the assumed LST from HJ-1B and MODIS acquired on the same date are correlated and comparable with each other. In this study, the STARFM was applied such that MOD11A1 and MOD11A2 were resampled and projected to the same coordinate system, pixel size, and image size as HJ-1B. The prediction method in the STARFM is given by the following equation:

$$
\begin{aligned}
T_{H}\left(x_{w / 2}, y_{w / 2}, t_{0}\right) & =\sum_{i=1}^{w} \sum_{j=1}^{w} \sum_{k=1}^{n} W_{i j k} \times\left(T_{M}\left(x_{i}, y_{j}, t_{0}\right)\right. \\
& \left.+T_{H}\left(x_{i}, y_{j}, t_{k}\right)-T_{M}\left(x_{i}, y_{j}, t_{k}\right)\right),
\end{aligned}
$$

where $T_{H}$ and $T_{M}$ represent the fine resolution LST data (HJ-1B) and coarse resolution LST data (MODIS LST), respectively; $t_{0}$ is the acquisition date, $t_{k}$ is the prediction date; $\left(x_{w / 2}, y_{w / 2}\right)$ is the central pixel; $\left(x_{i}, y_{j}\right)$ denotes the pixel location in both HJ-1B and MODIS LST data; and $W_{i j k}$ is the weight function that determines how much the similar pixel contributes to the estimated LST of the central pixel based on three measures: (1) the scale difference between $\mathrm{HJ}$ $1 \mathrm{~B}$ and MODIS LST data at their corresponding acquisition times; (2) the distance between the central pixel and the similar pixel at a given window location; and (3) the similarity difference between the central pixel at a given window location and pixels in a sliding window. For a more detailed description of the STARFM, please refer to the work of Gao et al. [27]. In the following parts, we call the LST directly from HJ-1B, MOD11A1, MOD11A2 as "observed LST", and LST derived from STARFM as "predicted LST".

In this study, in order to predict 8-day LST data at $300 \mathrm{~m}$ spatial resolution in each season according to the seasonal division of Shenzhen, the implementation consists of testing experiment and fusion experiment. In the testing experiment, we select a pair of HJ-1B LST and MOD11A1 data on $01 / 16 / 2015$ as the input base LST data at acquisition date $\left(t_{0}\right)$, and three MOD11A1 on 04/14/2015, 10/19/2015, 12/18/2015 as the input base LST data at acquisition date $\left(t_{k}\right)$ to generate the "predicted LST" based on the STARFM. We also selected three actual observed HJ-1B LST data on 04/14/2015, 10/18/ 2015, and $12 / 18 / 2015$ as the observed LST to verify the 
TABLE 2: The selected HJ-1B and MOD11A1 data for the testing experiment in this study.

\begin{tabular}{|c|c|c|c|c|}
\hline Experiment & Satellite data & Acquisition date & Input base LST data & Evaluate the predicted LST data \\
\hline \multirow{8}{*}{ Testing experiment } & HJ-1B & 16 Jan 2015 & $\sqrt{ }$ & \multirow{5}{*}{$\sqrt{ }$} \\
\hline & MOD11A1 & 16 Jan 2015 & $\sqrt{ }$ & \\
\hline & MOD11A1 & 14 Apr 2015 & $\sqrt{ }$ & \\
\hline & HJ-1B & 14 Apr 2015 & \multirow{3}{*}{$\sqrt{ }$} & \\
\hline & MOD11A1 & 19 Oct 2015 & & \\
\hline & HJ-1B & 18 Oct 2015 & & \multirow[t]{2}{*}{$\sqrt{ }$} \\
\hline & MOD11A1 & 18 Dec 2015 & \multirow[t]{2}{*}{$\sqrt{ }$} & \\
\hline & HJ-1B & 18 Dec 2015 & & $\sqrt{ }$ \\
\hline
\end{tabular}

TABle 3: The selected HJ-1B and MODIS LST data for the fusion experiment in this study.

\begin{tabular}{|c|c|c|c|c|c|}
\hline Season & Satellite & Date & $\begin{array}{l}\text { Day of the } \\
\text { year }\end{array}$ & $\begin{array}{c}\text { Input base LST data at the acquisition } \\
\text { date }\end{array}$ & $\begin{array}{l}\text { Input base LST data at the prediction } \\
\text { date }\end{array}$ \\
\hline \multirow{4}{*}{ Winter } & $\mathrm{HJ}-1 \mathrm{~B}$ & 16 Jan 2015 & 16 & $\sqrt{ }$ & \\
\hline & MOD11A1 & 16 Jan 2015 & 16 & $\sqrt{ }$ & \\
\hline & MOD11A2 & $\begin{array}{l}25 \text { Jan-01 Feb } \\
2015\end{array}$ & $025-032$ & & $\sqrt{ }$ \\
\hline & MOD11A2 & 02-09 Feb 2015 & $033-040$ & & $\sqrt{ }$ \\
\hline \multirow{3}{*}{ Spring } & $\mathrm{HJ}-1 \mathrm{~B}$ & 14 Apr 2015 & 104 & $\sqrt{ }$ & \\
\hline & MOD11A1 & 14 Apr 2015 & 104 & $\sqrt{ }$ & \\
\hline & MOD11A2 & 15-22 Apr 2015 & $105-112$ & & $\sqrt{ }$ \\
\hline \multirow{4}{*}{ Summer } & $\mathrm{HJ}-1 \mathrm{~B}$ & 18 Oct 2015 & 291 & $\sqrt{ }$ & \\
\hline & MOD11A1 & 19 Oct 2015 & 292 & $\sqrt{ }$ & \\
\hline & MOD11A2 & 24-31 Oct 2015 & $297-304$ & & $\sqrt{ }$ \\
\hline & MOD11A2 & 01-08 Nov 2015 & $305-312$ & & $\sqrt{ }$ \\
\hline \multirow{4}{*}{ Autumn } & $\mathrm{HJ}-1 \mathrm{~B}$ & 18 Dec 2015 & 352 & $\sqrt{ }$ & \\
\hline & MOD11A1 & 18 Dec 2015 & 352 & $\sqrt{ }$ & \\
\hline & MOD11A2 & 19-26 Dec 2015 & $353-360$ & & $\sqrt{ }$ \\
\hline & MOD11A2 & 01-08 Jan 2016 & 01-08 & & $\sqrt{ }$ \\
\hline
\end{tabular}

accuracy of the predicted LST. Additionally, the absolute average difference (AAD), root mean square error (RMSE), and coefficient of determination $\left(r^{2}\right)$ are computed between the predicted LST and actual observed LST to validate the accuracy of the predicted LST based on the STARFM. If the result is better in the testing experiment, we use four pairs of HJ-1B and MOD11A1 LST data on 01/16/2015, 04/14/2015, $10 / 18 / 2015$, and $12 / 18 / 2015$ as the input base LST data at acquisition date $\left(t_{0}\right)$ and replacing MOD11A1 at the predicted time $\left(t_{k}\right)$ with 8 -day LST data MOD11A2 in each season (Table 3 ) as the input data of the STARFM to fusion 8-day predicted LST in each season. Finally, 8-day predicted LST data at $300 \mathrm{~m}$ spatial in each season were averaged to seasonal values in the study area.

2.5. Classification of the Daytime LST Grade and Level. It is difficult to compare the predicted mean LST images from different seasons directly using absolute LST, owing to the fact that seasonal difference can affect the absolute LST values. However, the seasonal difference does not affect the distribution pattern of the LST. Therefore, a normalization technique [37] was used to compare the predicted mean LST in each season because the normalized LST with different seasons can rescale the LST to the same level between 0 and 1 , which can reduce the seasonal difference. Accordingly, the predicted mean LST values were normalized between 0 and 1 during different seasons in 2015. The normalized LST was calculated as follows:

$$
\mathrm{LST}^{\prime}=\frac{\mathrm{LST}_{i}-\mathrm{LST}_{\text {min }}}{\mathrm{LST}_{\text {max }}-\mathrm{LST}_{\text {min }}},
$$

where $\mathrm{LST}^{\prime}$ is the normalized LST value of the pixel $i, \mathrm{LST}_{i}$ is the LST of the pixel $i$, and $\mathrm{LST}_{\max }$ and $\mathrm{LST}_{\text {min }}$ are the maximum and minimum LSTs over the entire study area.

To reflect the seasonal daytime UTE dynamic directly, the normalized LST value was further classified as "high grade" (including very high, high, and subhigh), "medium grade" (medium and submedium), and "low grade" (low and very low) using the density slice technique. The classification criteria of the LST level are listed in Table 4.

2.6. Daytime LST Landscape Metrics Selection and Calculation. Versatile landscape metrics are widely used to measure and present the pattern of spatial characteristics of the LST [38]. Liu and Weng [39] proved that landscape metrics are effective to study the seasonal variations of the LST pattern in Indianapolis, USA. The effects of the spatial structure of the daytime LST in different seasons were quantitatively assessed using landscape metrics at both the class and landscape level, which included six class-based and four landscape-based metrics. The metrics for this study were chosen according to the following principles. They had 
TABLE 4: The classification criteria of the land surface temperature (LST) level.

\begin{tabular}{lccc}
\hline Grade & Level & Meaning & Range \\
\hline \multirow{2}{*}{ High } & 7 & Very high & $N_{i} \geq T_{\text {mean }}+2.5 \mathrm{~s}$ \\
& 6 & High & $\mathrm{T}_{\text {mean }}+1.5 \mathrm{~s} \leq \mathrm{N}_{\mathrm{i}}<T_{\text {mean }}+2.5 \mathrm{~s}$ \\
\multirow{2}{*}{ Medium } & 5 & Subhigh & $T_{\text {mean }}+0.5 \mathrm{~s} \leq N_{i}<T_{\text {mean }}+1.5 \mathrm{~s}$ \\
\hline \multirow{2}{*}{ Low } & 4 & Medium & $T_{\text {mean }}-0.5 \mathrm{~s} \leq N_{i}<T_{\text {mean }}+0.5 \mathrm{~s}$ \\
& 3 & Submedium & $T_{\text {mean }}-1.5 \mathrm{~s} \leq N_{i}<T_{\text {mean }}-0.5 \mathrm{~s}$ \\
\hline
\end{tabular}

Note. $T_{\text {mean }}$ is the mean LST value of all pixels after normalization, and $\mathrm{S}$ is the standard deviation.

to be (1) interpretable, (2) easily computed, (3) exhibit minimal redundancy, and (4) be important in both practice and theory [40]. FRAGSTATS 3.3, a software program designed to calculate landscape metrics, was selected for use. Table 5 lists the landscape metrics used in this study and provides their descriptions and equations. The class-based metrics were (1) Class Area (CA), (2) Patch Density (PD), (3) Largest Patch Index (LPI), (4) aggregation, (5) edge density, and (6) Perimeter-Area Fractal dimension (PAFRAC). The landscape-based metrics were (1) Shannon's Diversity Index, (2) Shannon's Evenness Index (SHEI), (3) Contagion Index (CONTAG), and (4) Interspersion and Juxtaposition Index (IJI). All landscape metrics were used to detect changes at the level of landscape seasonal variations.

\section{Results and Discussion}

3.1. Experimental Results. In this part, we tested the performance of the STARFM by fusing two LST data. The predicted LST was obtained at the $\mathrm{HJ}-1 \mathrm{~B}$ with a $300 \mathrm{~m}$ spatial resolution. In the testing experiment, MOD11A1 and $\mathrm{HJ}-1 \mathrm{~B}$ LST data were used as the input data. Figures 2(a) and 2(b) were the MOD11A1 and HJ-1B input base pair of observed LST data on 16 Jan 2015. Figures 2(c), 2(f), and 2(i) were the observed input base MOD11A1 data on 14 April 2015, 19 October 2015, and 18 December 2015, respectively. The corresponding predicted LST data are shown in Figures 2(e), $2(\mathrm{~g})$, and $2(\mathrm{k})$. The actual observed HJ-1B LST data (Figures 2(d), 2(g), and 2(j)) can be used to evaluate the predicted LST results.

Compared to the predicted LST from two different LST data, we can see that the predicted LST images of the third column images in Figure 2 are visually similar to the actual observed HJ-1B LST data, corresponding to the second column. Table 6 displays the $r^{2}$, RMSE, and AAD between the predicted and observed LSTs. The values of RMSE and AAD are smaller than 4.88 and 4.77 , respectively, whereas the $r^{2}$ are higher than 0.83 and significant at the 0.001 level.

The accuracy evaluations in the testing experiment suggest that the predicted LST in different date is in good agreement with the actual observed HJ-1B LST data. Therefore, we can use the abovementioned four pairs of actual observed MOD11A1 and HJ-1B LST data on 16 Jan 2015, 14 Apr 2015, 18 Oct 2015, and 18 Dec 2015 as the input base LST data at acquisition date $\left(t_{0}\right)$ and with 8-day LST data MOD11A2 (Table 3) in each season at the predicted time $\left(t_{\mathrm{k}}\right)$ as the input data of the STARFM to fusion 8-day predicted
LST. The predicted winter LSTs were averaged over the day of year 16, 025-032, and 033-040 in 2015. The predicted spring LSTs were averaged over the day of year 104 and 105-112 in 2015. The predicted summer LSTs were averaged over the day 291, 297-304, and 305-312 in 2015. The predicted autumn LSTs were averaged over the days 352 and 353-360 in 2015 and $01-08$ in 2016.

Spatial distribution of the predicted daytime LST in Shenzhen representing four seasons (winter, spring, summer, and autumn) is shown in Figure 3. We can see that the STARFM can predict the seasonal LST in Shenzhen at the HJ-1B spatial scale by combining the high spatial resolution of HJ-1B LST data and frequent coverage of MOD11A2. Compared with the traditional method, the generated synthetic seasonal LST images based on the STARFM in this study can depict more spatial detailed information in different seasons. Through the abovementioned computation, the daytime LSTs ranged from 13.43 to $29.77^{\circ} \mathrm{C}$ in the winter, 13.88 to $40.73^{\circ} \mathrm{C}$ in the spring, 20.11 to $43.51^{\circ} \mathrm{C}$ in the summer, and 249 and 12.49 to $22.88^{\circ} \mathrm{C}$ in the autumn, respectively.

\subsection{Analysis of the Seasonal Daytime LST and Land Cover} Types. Daytime LSTs in Shenzhen during different seasons of the year 2015 were quantitatively generated based on the STARFM, and their spatiotemporal distribution is shown in Figure 3. In order to reflect the spatial distribution of daytime LSTs during four seasons, high-spatial resolution (17 m) Google Earth imagery in 2015 was used along with the supervised maximum likelihood classification method to obtain a detailed land use reference map (Figure 4) that includes seven land cover types: ISA, forest land, garden land, plough land, grass land, unused land, and water body. We think this map would be of assistance in helping to illustrate how daytime LSTs vary spatially.

In all seasons, daytime LSTs showed an increasing trend from east to west. All higher daytime LSTs values were mainly located in important transportation hubs (Yantian Port in the south, Shekou Port in the southwest, and Baoan International Airport in the western part of the study area), followed by commercial areas (Qianhai and Futian-Luohu Urban Municipal Centers), industrial areas (Western Industrial Cluster), and residential areas (Central Urban Cluster), while the lowest occurred in green areas and water body areas. For example, Dapeng Peninsula, located in southeastern Shenzhen, is a largely mountainous area along 
TABLE 5: Landscape metrics selected in this study.

\begin{tabular}{|c|c|c|}
\hline $\begin{array}{l}\text { Metrics } \\
\text { (abbreviation) }\end{array}$ & Level & Description and equation \\
\hline Class area (CA) & Class & $\begin{array}{l}\text { The total area of a given patch type in the entire landscape (unit: ha) } \\
\qquad \sum_{i j}^{n} \text { is the area of patch } i j\end{array}$ \\
\hline Patch density (PD) & Class & $\begin{array}{l}\text { The number of patches divided by the total area of the landscape (unit: } n / 100 \text { ha) } \\
\left(n_{i} / A\right)^{*} 10^{6} \\
n_{i} \text { is the number of patches in the landscape for patch class } i \text {; } A \text { is the total landscape area }\end{array}$ \\
\hline $\begin{array}{l}\text { Largest patch index } \\
\text { (LPI) }\end{array}$ & Class & $\begin{array}{l}\text { The percentage of the landscape comprised by the largest patch (unit: \%) } \\
\qquad\left(\max \left(a_{i j}\right)_{j=1}^{n} / A\right)^{*} 100\end{array}$ \\
\hline Aggregation (AI) & Class & $\begin{array}{l}\text { Contagion index: the focal class, not adjacencies with other patch types (unit: \%) } \\
\qquad\left(g_{i i} /\left(\max -g_{i i}\right)\right)^{*} 100 \\
g_{i i} \text { is the number of like adjacencies between pixels of patch class } i \text { based on the single-count method; } \\
\max -g_{i i} \text { is the max value of } g_{i i}\end{array}$ \\
\hline Edge density (ED) & Class & $\begin{array}{l}\text { Total length of all edge segments of corresponding patch per hectare (unit: } \mathrm{m} / \mathrm{ha} \text { ) } \\
\qquad\left(\sum_{j=1}^{n} e_{i j} / A\right)^{*} 10000 \\
\qquad e_{i j} \text { is the total length of edges for patch class } i \text { and patch } j \text { in the landscape }\end{array}$ \\
\hline $\begin{array}{l}\text { Perimeter-area } \\
\text { fractal dimension } \\
\text { (PAFRAC) }\end{array}$ & Class & $\begin{array}{l}2 /\left\{\left\{\left[n_{i}^{*} \sum_{j=1}^{n}\left(\ln P_{i j}^{*} \ln a_{i j}\right)\right]-\left[\left(\sum_{j=1}^{n} \ln P_{i j}\right)\left(\sum_{j=1}^{n} \ln a_{i j}\right)\right]\right\} /\left\{\left[n_{i}^{*} \sum_{j=1}^{n} \ln \left(P_{i j}\right)^{2}\right]-\left(\sum_{j=1}^{n} \ln P_{i j}\right)^{2}\right\}\right\} \\
\qquad P_{i j} \text { is the perimeter of patch } i j \\
\text { A diversity in the whole community ecology (unit: none) }\end{array}$ \\
\hline $\begin{array}{l}\text { Shannon's diversity } \\
\text { index (SHDI) }\end{array}$ & Landscape & $\begin{array}{c}P_{i} \text { is the proportion of landscape occupied by patch class } i ; \mathrm{m} \text { is number of path classes present in the } \\
\text { landscape }\end{array}$ \\
\hline $\begin{array}{l}\text { Shannon's } \\
\text { evenness index } \\
\text { (SHEI) }\end{array}$ & Landscape & $\begin{array}{l}\text { A measurement of patch diversity (unit: none) } \\
\qquad-\sum_{i}^{m}\left(P_{i}^{*} \ln P_{i}\right) / \ln (m)\end{array}$ \\
\hline $\begin{array}{l}\text { Contagion index } \\
\text { (CONTAG) }\end{array}$ & Landscape & $\begin{array}{c}\text { Aggregation of all patch types (unit: none) } \\
\left\{1+\left(\sum_{i=1}^{m} \sum_{k=1}^{m}\left[P_{i}^{*}\left(P_{i k} / \sum_{k=1}^{m} g_{i k}\right)\right]^{*}\left(\ln P_{i}\left(g_{i k} / \sum_{k=1}^{m} g_{i k}\right)\right)\right) /(2 \ln (m))\right\}^{*} 100 \\
g_{i k} \text { is the number of like adjacencies between pixels of patch class } k \text { based on the double-count method }\end{array}$ \\
\hline $\begin{array}{l}\text { Interspersion and } \\
\text { juxtaposition index } \\
\text { (IJI) }\end{array}$ & Landscape & $\begin{array}{l}\text { Observed interspersion divided by maximum interspersion for the patch classes in a landscape (unit: \%) } \\
\qquad\left(-\sum_{i=1}^{m} \sum_{k=i+1}^{m}\left[\left(e_{i k} / E\right) \ln \left(e_{i k} / E\right)\right]\right) /(\ln \{0.5[m(m-1)]\})^{*} 100 \\
e_{i k} \text { is the total length of edge in the landscape between patch classes } i \text { and } k ; E \text { is the total length of edge in } \\
\text { the landscape }\end{array}$ \\
\hline
\end{tabular}

the coast. In winter, higher daytime LSTs were mainly concentrated in business and industrial districts (Baoan, Nanshan, Guangming, and Longgang), while in spring and summer, higher daytime LSTs were concentrated in traditional commercial centers of the Guangming District and industrial areas of Songgang and Shajing Street. In autumn, the highest daytime LSTs were in the Qianhai and FutianLuohu Urban Municipal Centre which are traditional businesses and political area.

The distinctive daytime LST patterns in each season are associated with the thermal characteristics of different land cover types. In this study, the seasonal daytime LST of each land cover types was derived in order to analyse the relationships between land cover and daytime LST in different season. The results are shown in Figure 5. It was found that daytime LST in each land cover type showed an increasing trend form winter to summer and decreased from summer to autumn. The daytime LSTs were higher in summer and spring, but lower in autumn and winter. The ISA, which was mainly linked with the industrial, commercial, and residential areas, exhibited the highest daytime LST over all seasons, followed by plough and unused land. The lowest LSTs in daytime were observed in water bodies, followed by grasslands, gardens, and forests. These results suggest that the frequent human activities and high-population density land cover types may result in higher daytime LST in each season. Water bodies, grasslands, gardens, and forests may alleviate the UTE deteriorates owing to the fact that the presence of vegetation can generate a cooling effect on the daytime LST by increasing the latent heat fluxes via transportation [41].

\subsection{Changes in Landscape Metrics of Daytime LSTs in Different} Seasons. In spring and summer, the high-grade daytime LSTs were centered in the Western Industrial Cluster (Figure 6). In contrast, the vegetation is very dense during spring and summer in southeastern Shenzhen, which is covered by mountains, so this area has relatively low daytime LSTs. Few high-grade daytime LSTs form in winter and autumn, and these are extremely scattered. However, very high-level daytime LSTs were detected in all seasons and were concentrated over the ports of Yantian and Shekou, as well as at the Baoan International Airport, underscoring the strong effects of anthropogenic activities on the UTE.

Six class-based metrics were selected to measure daytime LSTs, targeting three levels of daytime LSTs, subhigh, high, and very high, reflecting their dynamic change within four 


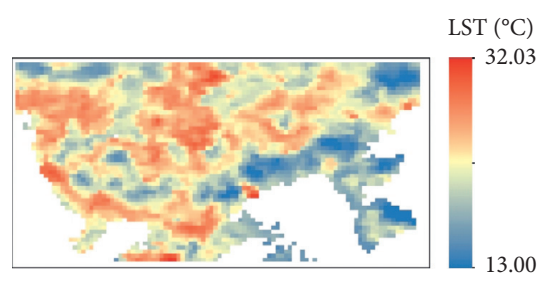

(a)

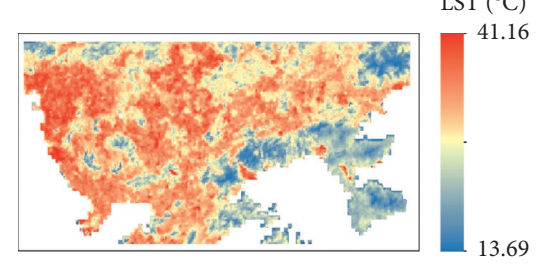

(d)

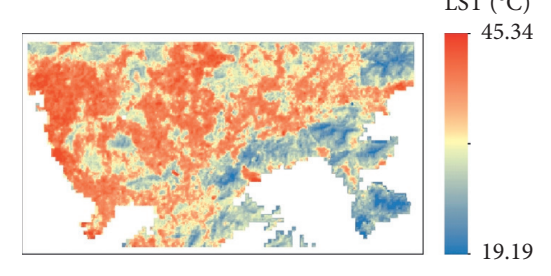

(g)

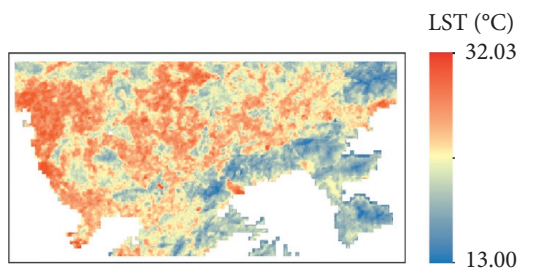

(b)

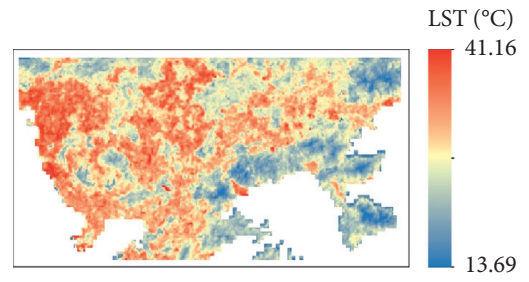

(e)

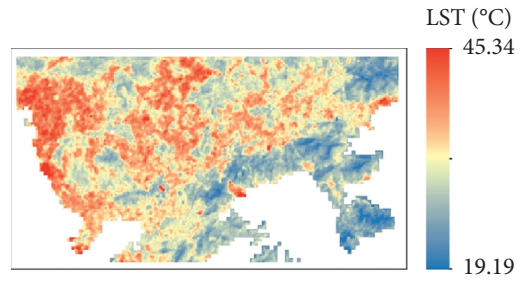

(h)

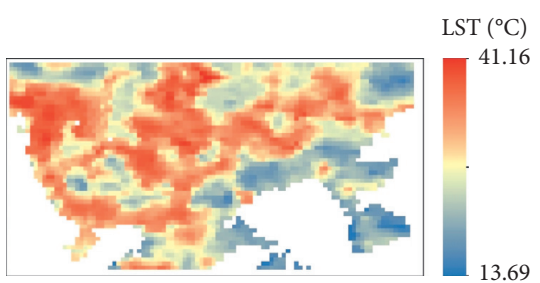

(c)

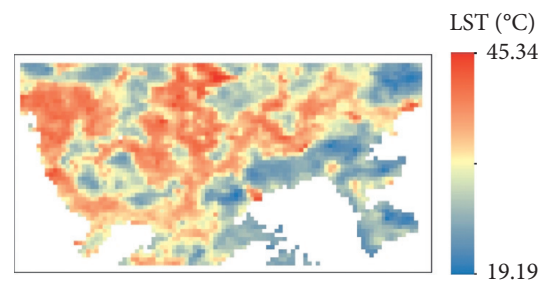

(f)

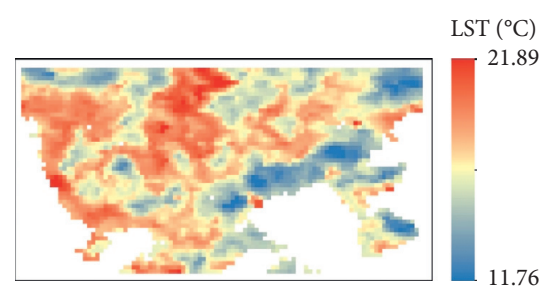

(i)

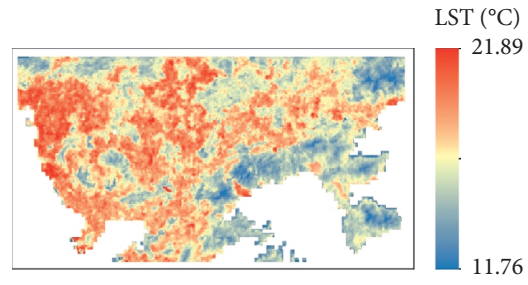

(j)

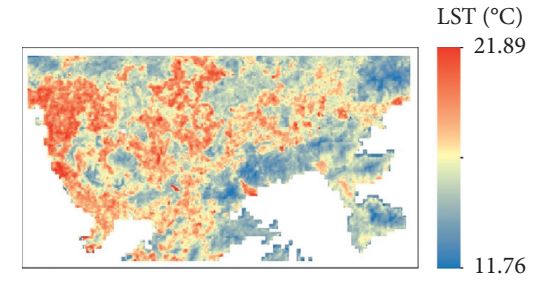

(k)

FIGURE 2: The observed and predicted LSTs. (a) and (b) are the observed MOD11A1 and HJ-1B LST on 16 June 2015; (c), (d), and (e) are the observed MOD11A1, actual observed HJ-1B LST, and predicted LST on 14 April 2015, respectively. (f), (g), and (h) are the observed MOD11A1 on 19 October 2015, actual observed HJ-1B LST on 18 October 2015, and predicted LST on 18 October 2015, respectively. (i), (j), and $(\mathrm{k})$ are the observed MOD11A1, actual observed HJ-1B LST, and predicted LST on 18 December 2015, respectively.

TABLE 6: $r^{2}$, RMSE, and AAD between the predicted LST and actual observed HJ-1B LST in the testing experiment.

\begin{tabular}{lccc}
\hline Indicator & 14 Apr 2015 & 18 Oct 2015 & 18 Dec 2015 \\
\hline$r^{2}$ & 0.86 & 0.83 & 0.88 \\
RMSE $(\mathrm{K})$ & 4.41 & 4.88 & 3.71 \\
AAD $(\mathrm{K})$ & 4.19 & 4.77 & 3.50 \\
\hline
\end{tabular}

Note. Significant at 0.01 level $(p<0.001)$.

seasons in 2015 (Figure 7). In general, daytime LSTs develop almost consistently with the locations of urbanized areas; however, what really leads to environmental problems is the high intensity and a certain scale of high-grade and highlevel daytime LSTs on landscape patches. We found that Class surface Areas (CAs) of levels 5, 6, and 7 of daytime LSTs all increased from 10120, 11960, and 7360 for winter to 14721, 18401, and 10118 for summer (Figure 7(a)). The CAs, then, began to decrease from summer to 9200, 11040, and
6440 in autumn. It indicates that daytime LSTs in summer contributed the most heat to the UTE in Shenzhen in 2015, followed by spring and winter and, finally, autumn. For the LPI, levels 5 and 6 increased from winter to summer and decreased in autumn, while level 7 decreased from winter to spring and increased from spring to autumn (Figure $7(\mathrm{~b})$ ). This suggests that the aggregation and dominance of level 5 and 6 patches increased from winter to summer; however, aggregation and dominance of level 7 patches were the lowest in spring. While level 7 had the lowest value in the shape index, the PAFRAC, it had the highest value in the AI, suggesting maximum aggregation and the lowest complexity of shapes (Figures $7(\mathrm{c})$ and $7(\mathrm{~d})$ ). Figures $7(\mathrm{e})$ and $7(\mathrm{f})$ illustrate that PD and ED of levels 5, 6, and 7 showed an increasing trend from winter to autumn in 2015. PD and ED increased significantly from winter to summer and decreased in autumn. All these showed that the degree of fragmentation of levels 5, 6, and 7 increased obviously from 


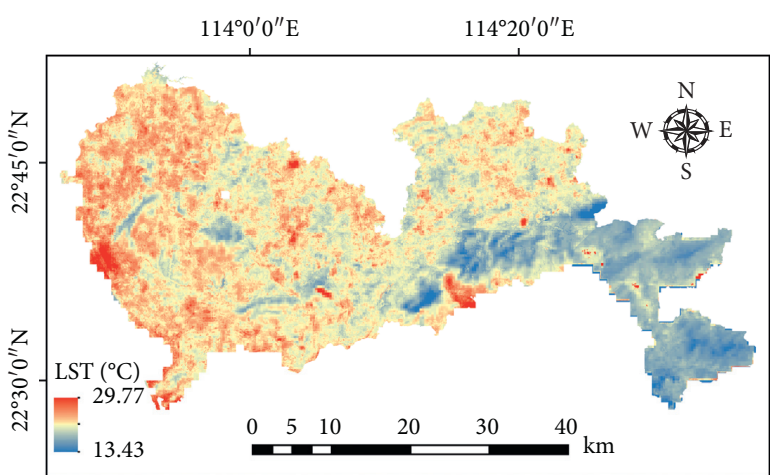

(a)

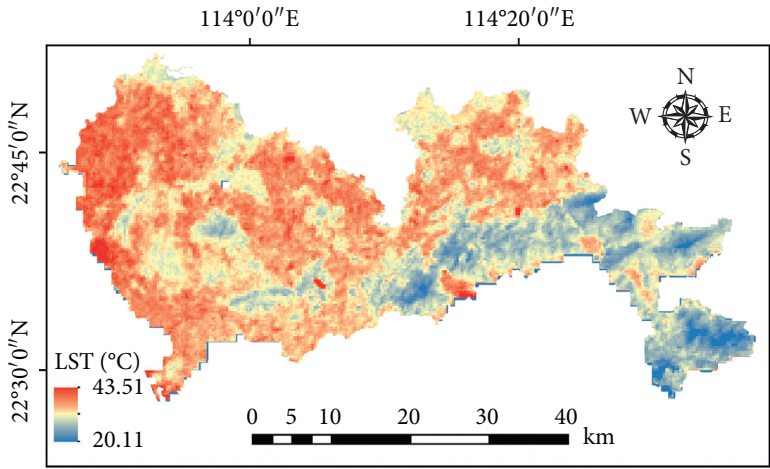

(c)

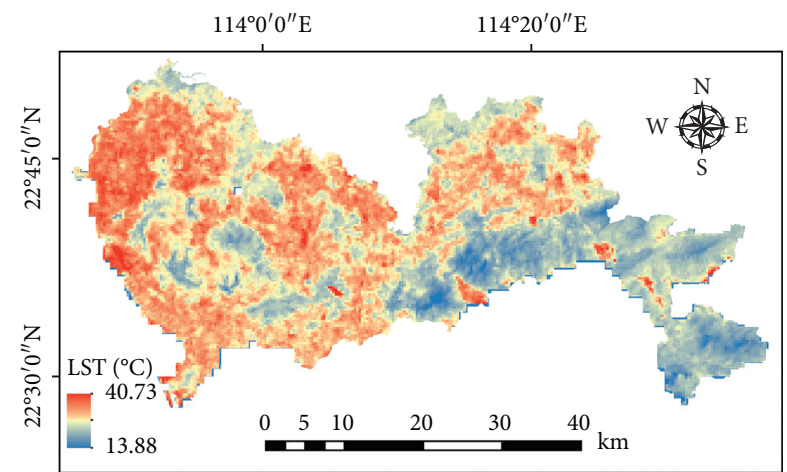

(b)

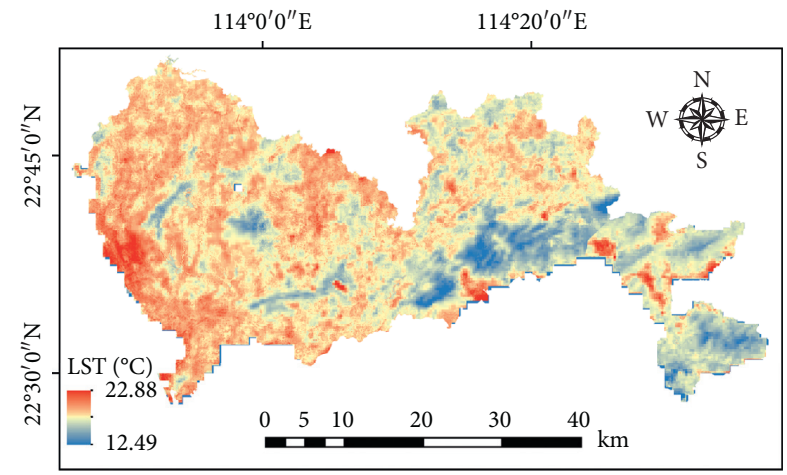

(d)

FIGURE 3: Spatial distribution of predicted daytime land surface temperatures in the (a) winter, (b) spring, (c) summer, and (d) autumn.

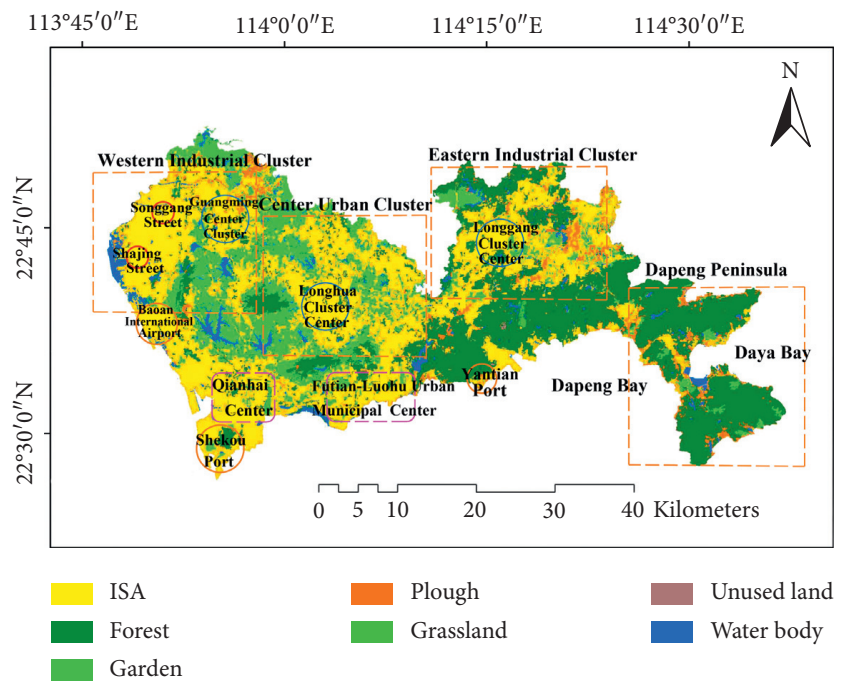

FIGURE 4: Detailed land use reference map in Shenzhen, 2015.

winter to summer and decreased in autumn, which could lead to the trend of cluster distribution in autumn.

Four landscape-based metrics were selected to measure daytime LSTs in each season. Shannon's Diversity Index (SHDI) and Shannon's evenness Index (SHEI) decreased from winter to summer and increased in autumn; this indicated that the mixture of ISA and other land use types including their abundance can be beneficial for relieving or reducing the daytime LSTs (Figures $8(\mathrm{a})$ and $8(\mathrm{~b})$ ). The

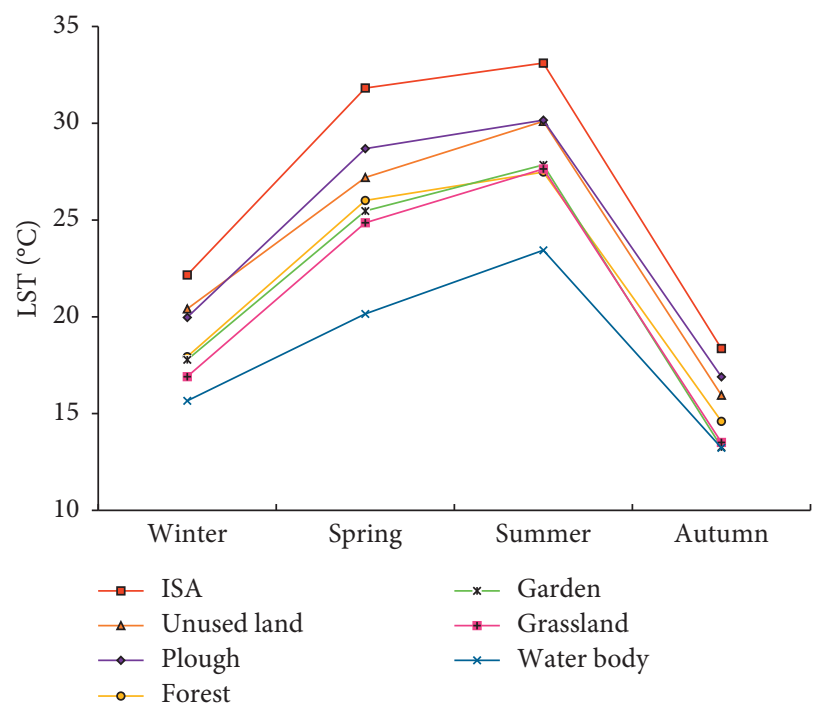

FIGURE 5: The seasonal variations of daytime LST by different land cover types in Shenzhen, 2015.

CONTAG index reflected the extension of different types of landscape patches and the degree of aggregation. During winter to autumn, the CONTAG of daytime LSTs landscapes increased from winter to summer (Figure 8(c)), showing that landscapes with a few contiguous and large patches will make high values of contagion, determining the UTE. The IJI values (Figure 8(d)) increased form winter to summer and decreased in autumn, which reflected the simple structure of 


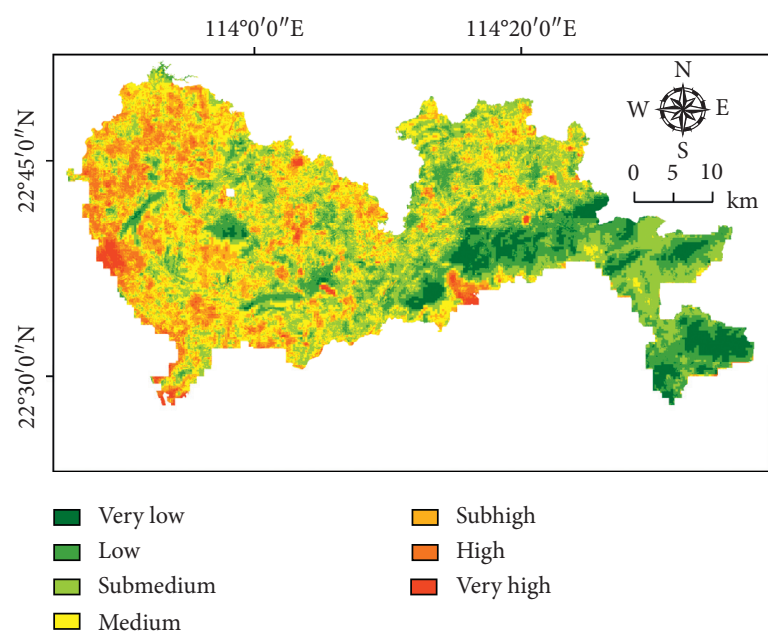

(a)

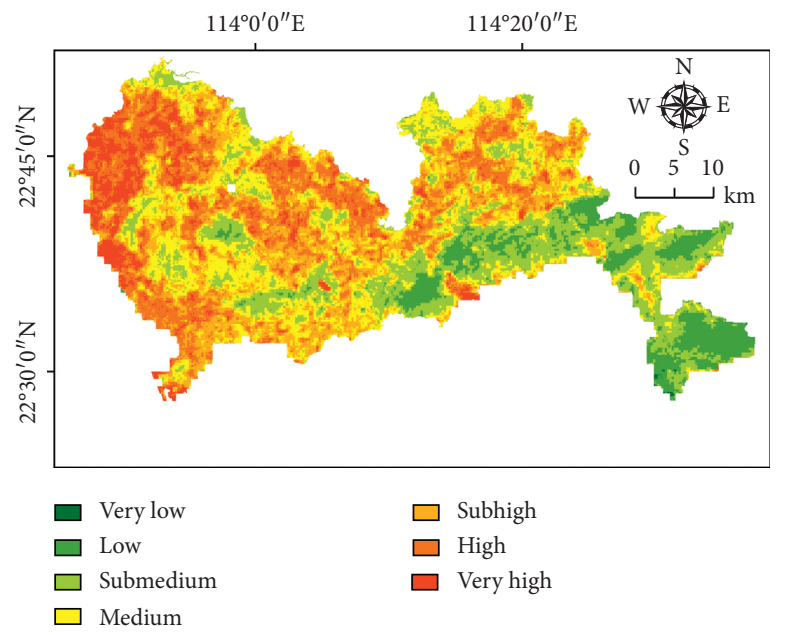

(c)

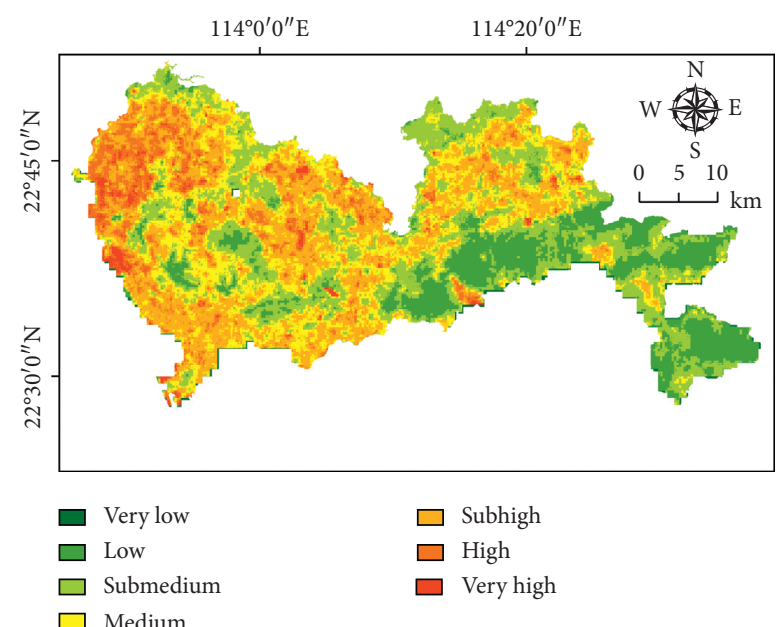

(b)

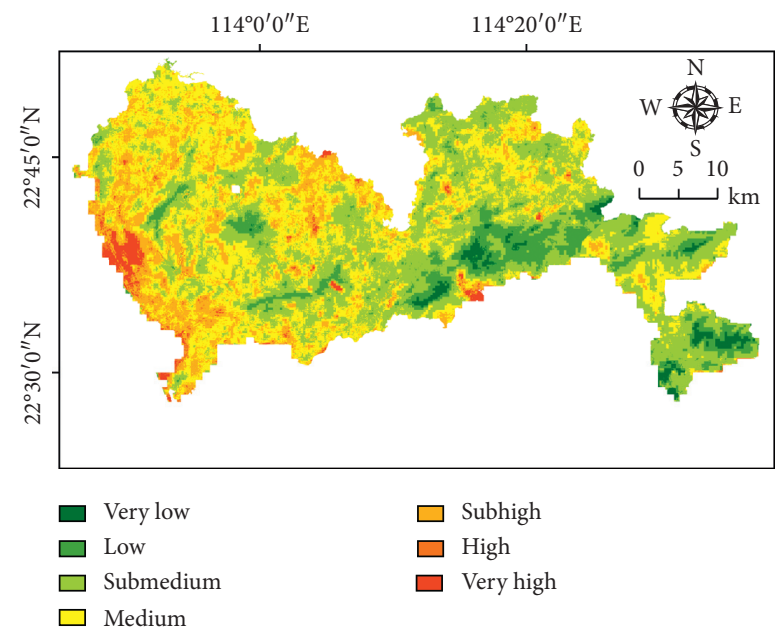

(d)

FIgURE 6: Spatial distribution of the level of daytime LSTs in Shenzhen. Spatial distribution of the level of daytime LSTs in (a) winter, (b) spring, (c) summer, and (d) autumn.

the daytime LSTs and the decrease in landscape heterogeneity at the overall landscape level in autumn.

3.4. Possible Driving Factors Underlying the Seasonal Variations of Daytime LSTs. Several climatic and anthropogenic factors were found to cause major effects on the seasonal patterns of LSTs in Shenzhen. In order to investigate the driving factors affecting daytime LSTs, seasonal daytime (10: 00-12:00 a.m.) wind speed and average relative humidity data from 44 weather stations that are distributed throughout the Shenzhen area were used to calculate the seasonal average daytime value for each weather station. Then, using the Kriging Gaussian method, which is commonly applied to interpolate the data, the seasonal daytime spatial distribution of the average relative humidity (Figure 9) and wind speed during 2015 (Figure 10) were calculated.

We found that daytime LSTs were positively correlated with relative humidity in four seasons. From Figure 9, it can be seen that the mean daytime (10:00-12:00 a.m.) relative humidity value was higher in summer (65-85\%) and spring $(60-80 \%)$ and lower in autumn (50-65\%) and winter (55-70\%). This agrees with the findings of Zhao et al. [42] that, in the humid eastern United States, high humidity will result in the UHI effect by increasing the temperature. The reason can be explained by the soil moisture difference. For example, according to mean daytime (08:00-20:00) precipitation data provided by the Meteorological Bureau of Shenzhen Municipality, Shenzhen rainfall in summer comprised as much as $85 \%$ of the total annual rainfall, while the summer daytime mean precipitation in 2015 was $5.43 \mathrm{~mm} /$ day and was only $2.33 \mathrm{~mm} /$ day in autumn. This also agrees with the findings of Zhou et al. [43] that a close and positive relationship exists between precipitation and SUHIs in China. Therefore, the relatively high daytime precipitation and relative humidity in Shenzhen normally reflected high soil moisture content that had a higher heat capacity in summer than other seasons, resulting in higher daytime LST differences between ISA and non-ISA. Another factor is that daytime LSTs were negatively correlated to wind speed in all four seasons (Figure 10). Many studies have 


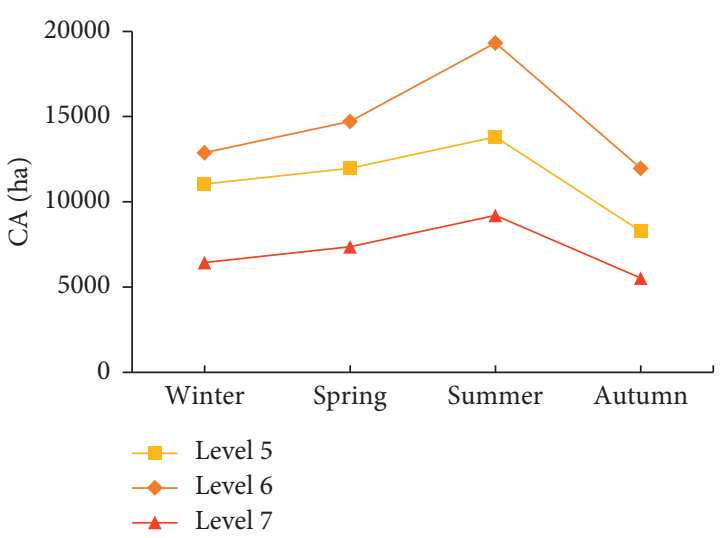

(a)

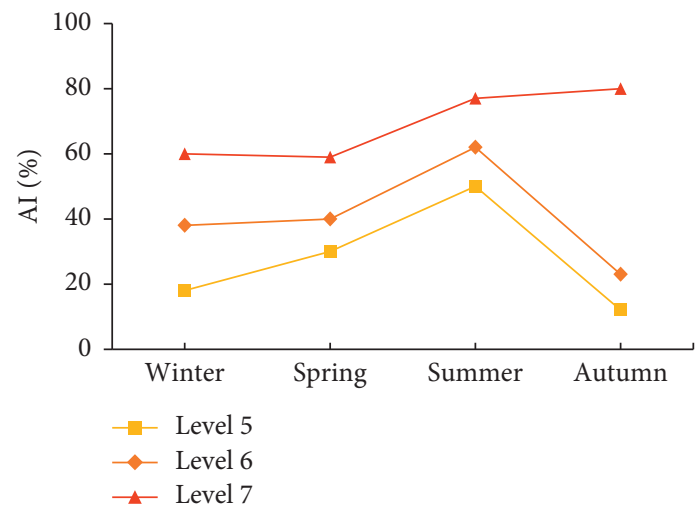

(c)

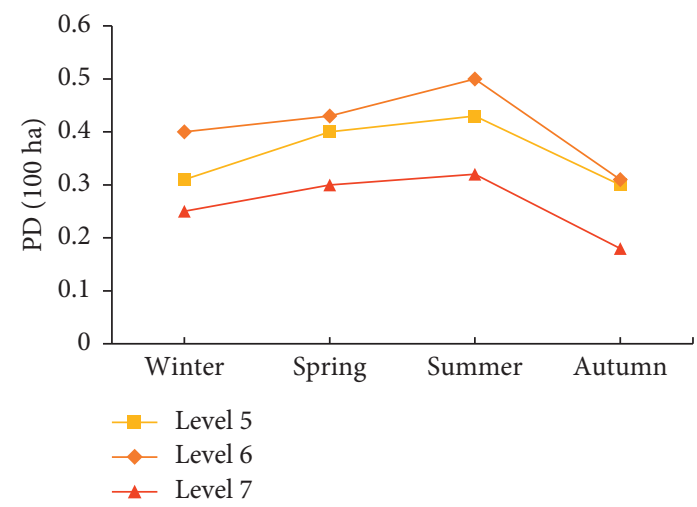

(e)

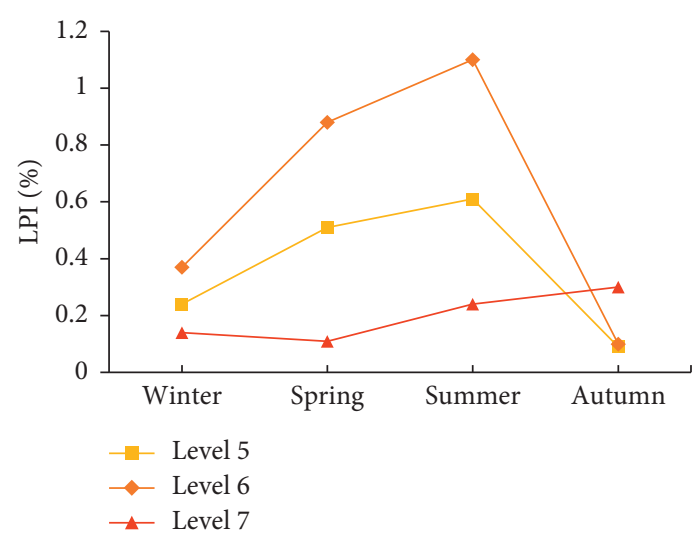

(b)

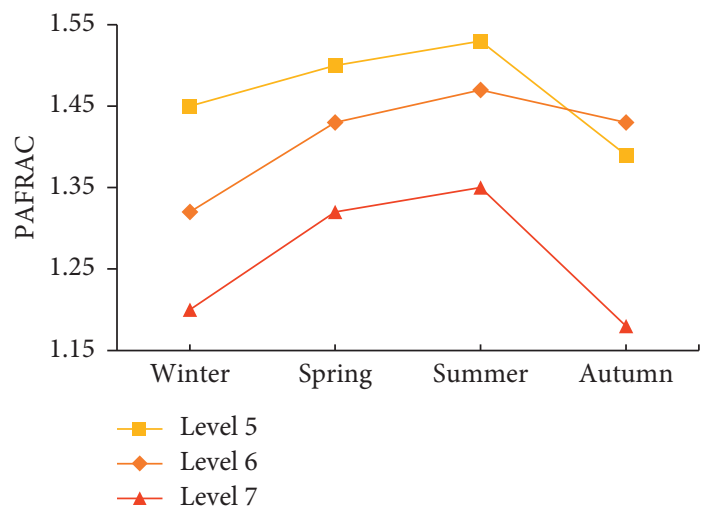

(d)

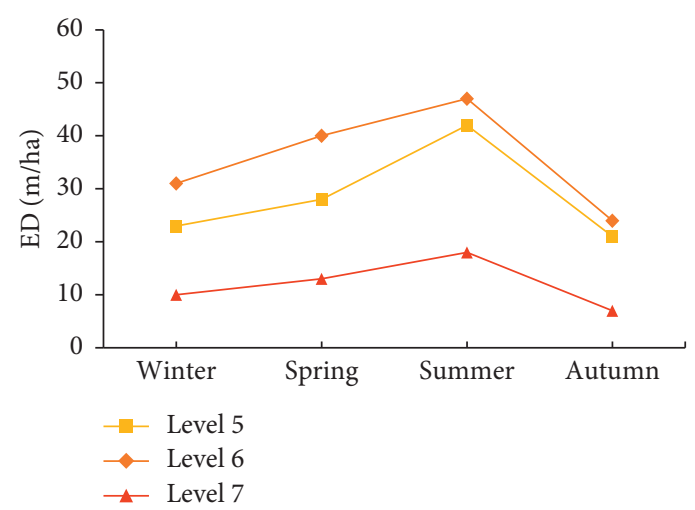

(f)

Figure 7: The changes of daytime LST landscape metrics at the class level in four seasons of 2015. (a) Class surface area (CA). (b) Largest patch index (LPI). (c) Aggregation (AI). (d) Perimeter-area fractal dimension (PAFRAC). (e) Patch density (PD). (f) Edge density (ED).

reported that the urban LST and SUHI intensity were negatively correlated with wind speed [44]. This result is also appropriate for Shenzhen because the daily daytime wind speed value is higher in winter $(2.1-15.2 \mathrm{~m} / \mathrm{s})$ and autumn $(2.8-16.5 \mathrm{~m} / \mathrm{s})$ and lower in summer $(1.8-7.0 \mathrm{~m} / \mathrm{s})$ and spring $(2.1-9.1 \mathrm{~m} / \mathrm{s})$. Rajagopalan et al. [45] found that Muar, a tropical city in Malaysia, experienced a cooling effect of wind speed that can decrease the UHI effect and mitigate the adverse effects on human thermal comfort. Another driving factor that can also affect daytime LSTs in each season was the sensible energy partition of solar radiation. Huge quantities of solar radiation are reradiated and mainly stored in ISA; this depends strongly on the soil conditions, vegetation, sky view factor, and construction material. Besides this, the effects of change in the seasonal urban biophysical composition increased aerosols in the surface net shortwave in summer and spring more than in winter and autumn because of the stronger summer time incoming solar radiation. In Shenzhen, stronger solar radiation is absorbed by urban areas in summer and spring. The daily daytime mean solar radiation value was $13.3-16.2 \mathrm{MJ} / \mathrm{m}^{2}$ in summer and spring and decreased to $9.8-11.6 \mathrm{MJ} / \mathrm{m}^{2}$ in autumn and 


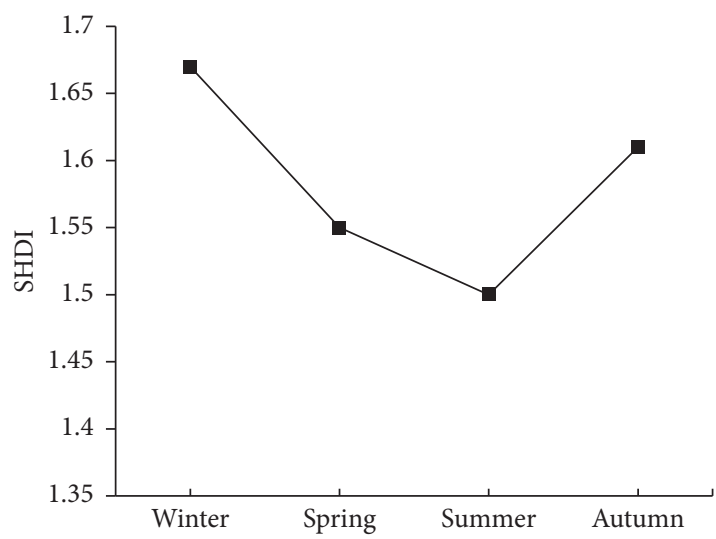

(a)

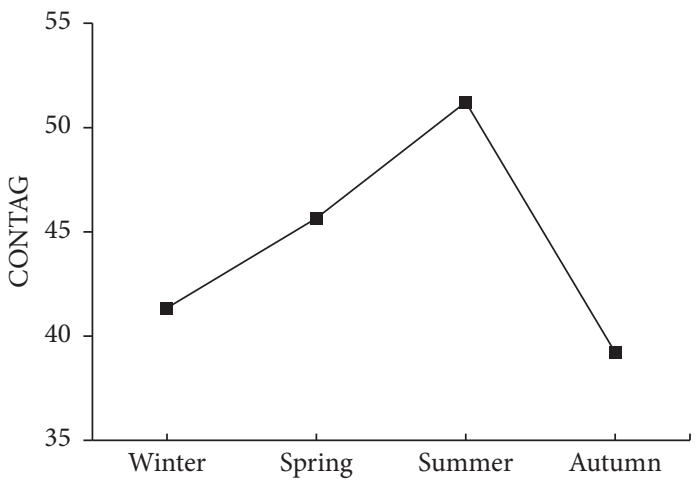

(c)

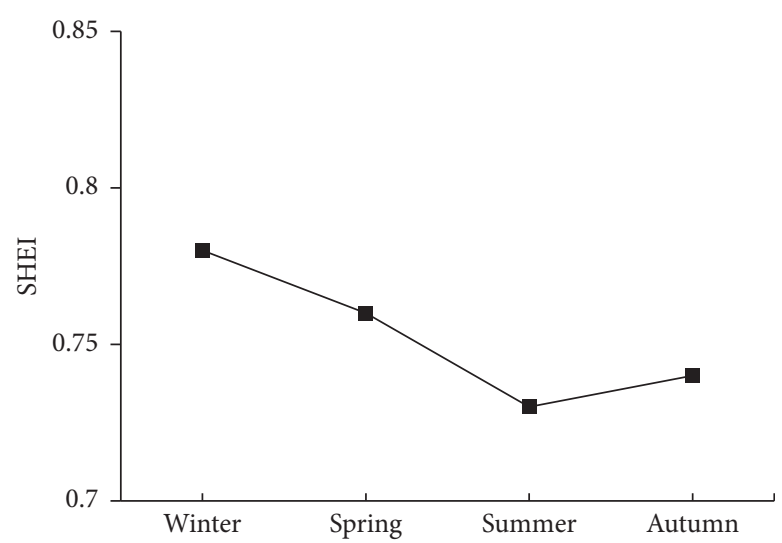

(b)

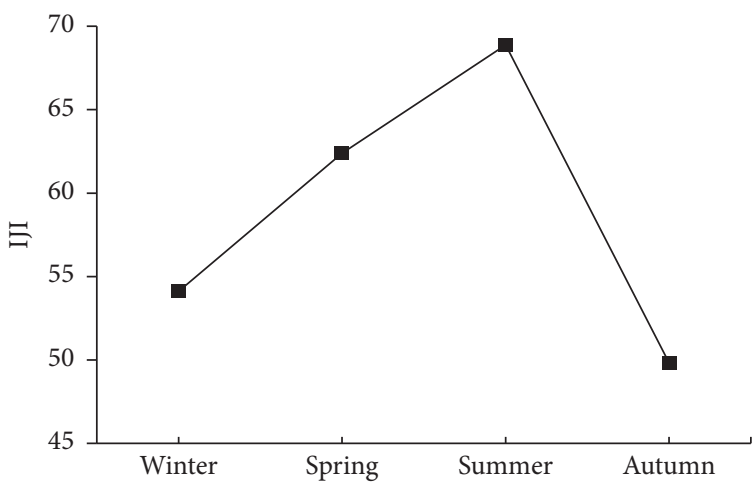

(d)

Figure 8: The changes of daytime LST landscape metrics at the landscape level in different seasons of 2015: (a) Shannon's Diversity Index (SHDI); (b) Shannon's evenness Index (SHEI); (c) Contagion Index (CONTAG); and (d) Interspersion and Juxtaposition Index (IJI).

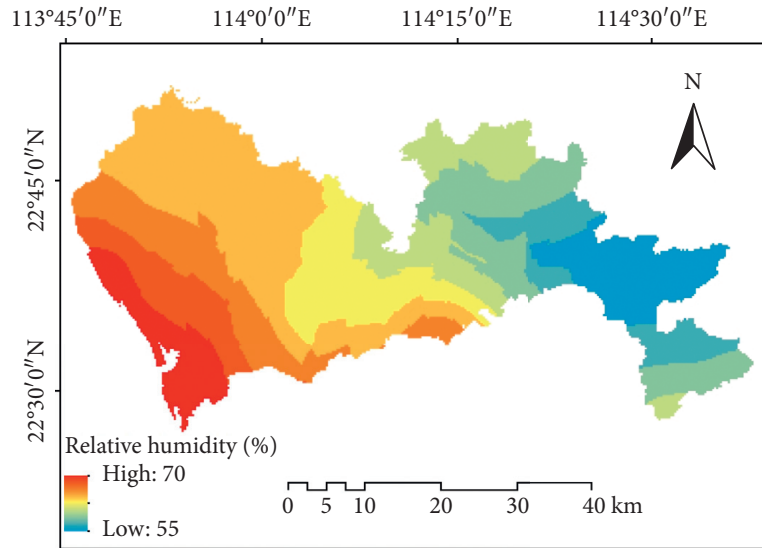

(a)

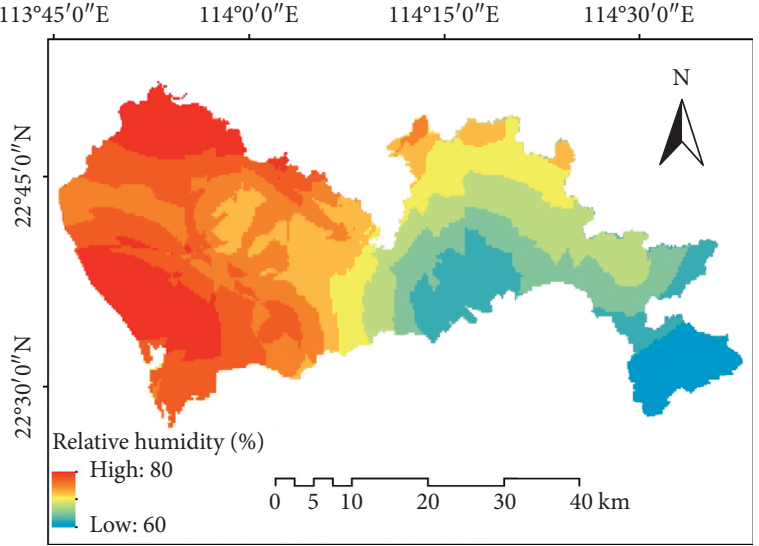

(b)

Figure 9: Continued. 


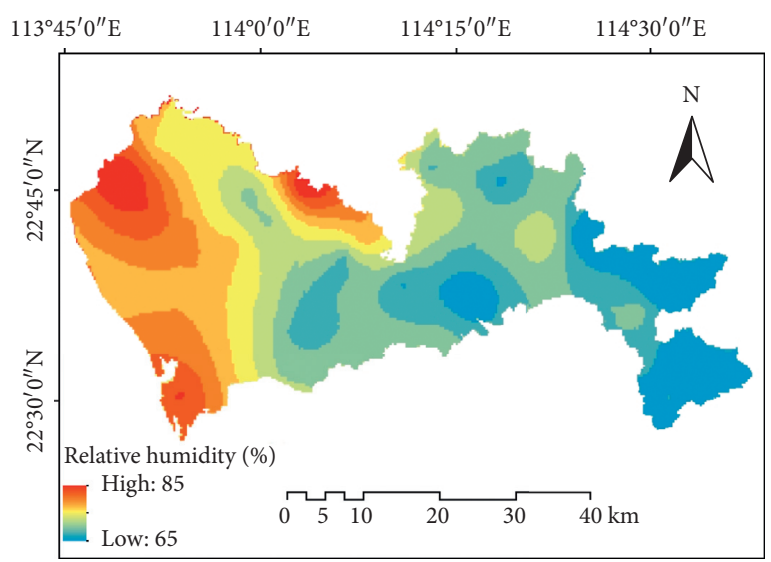

(c)

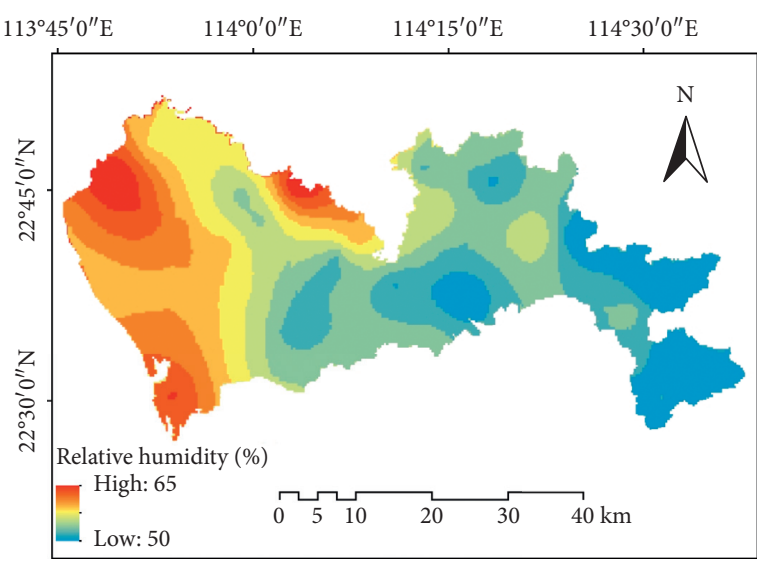

(d)

FIGURE 9: Spatial distribution of the mean daytime (10:00-12:00 a.m.) relative humidity during (a) winter, (b) spring, (c) summer, and (d) autumn in Shenzhen, 2015.

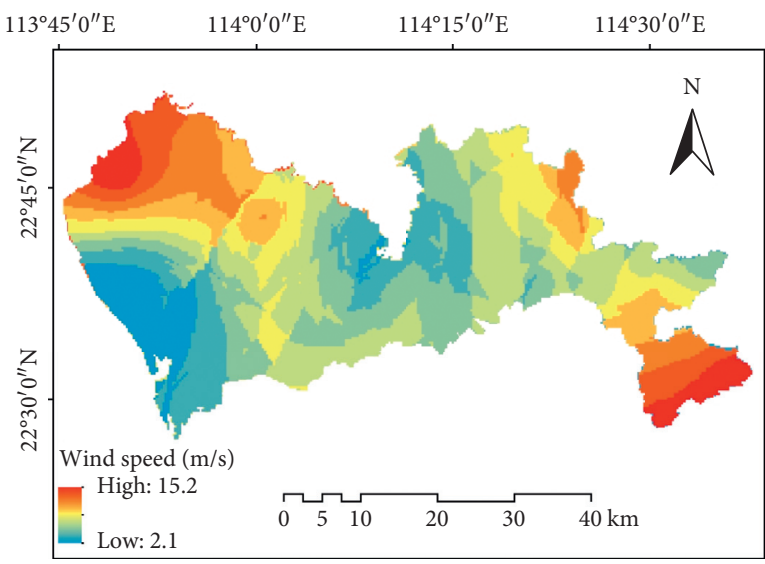

(a)

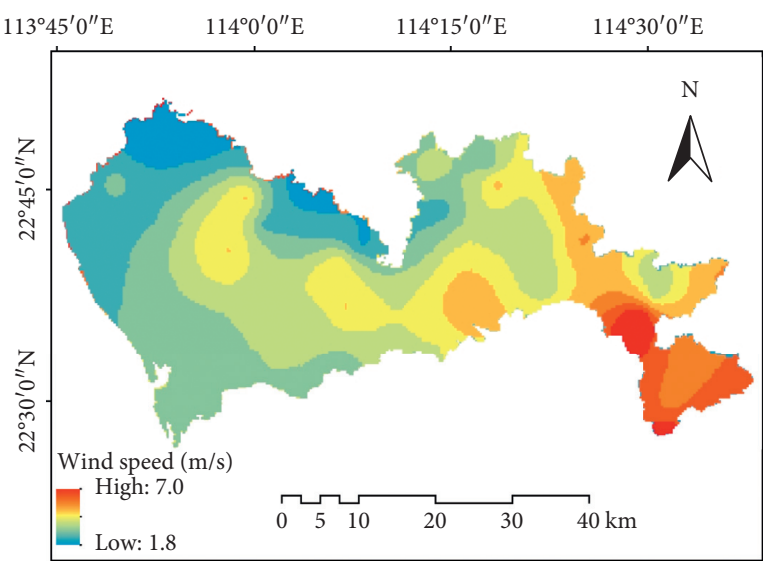

(c)

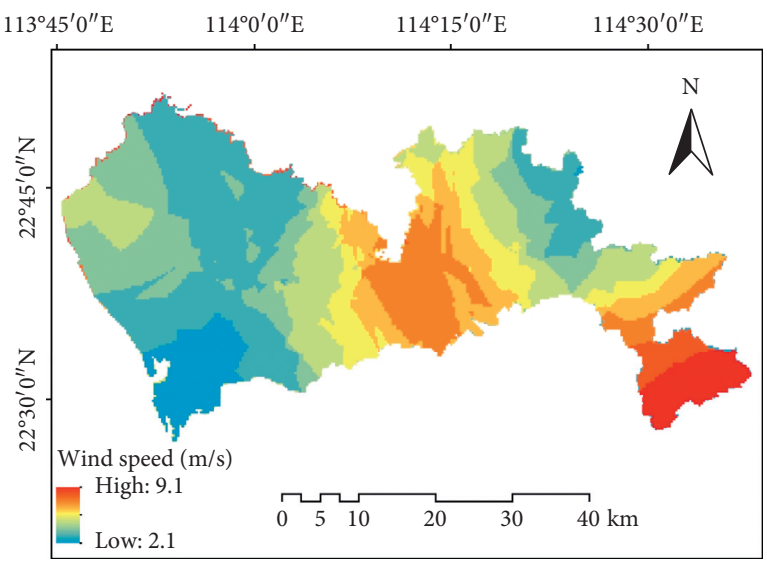

(b)

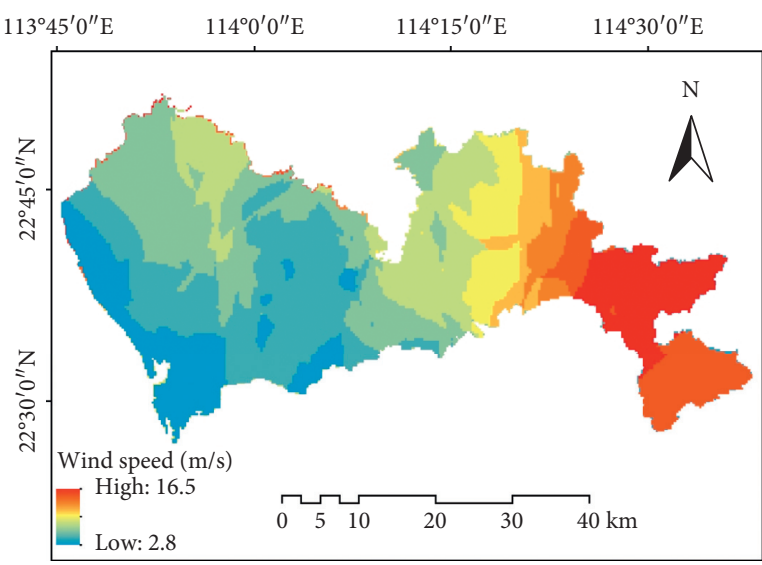

(d)

FIGURE 10: Spatial distribution of the mean daytime (10:00-12:00 a.m.) wind speed (m/s) during (a) winter, (b) spring, (c) summer, and (d) autumn in Shenzhen, 2015.

winter. Apart from climatic reasons, anthropogenic heat released from vehicles, air conditioners, power plants, and other heat sources provide another factor that influences the daytime UTE, especially tropical cities that often have long summers and short winters [46]. For example, in 2015, the average monthly electricity consumption in Shenzhen during the summer daytime was about 6.5 billion $\mathrm{kWh}$, and in winter, this was about 2.5 billion $\mathrm{kWh}$. In order to 
mitigate anthropogenic heat release, we need to reduce the consumption of electricity by air conditioners by planting vegetation on the exterior walls of buildings or by using highly reflective materials for buildings [47].

3.5. Limitations. In this study, the STARFM method was used to predict seasonal daytime LST data in Shenzhen, 2015. Compared to the original HJ-1B and MODIS LST data, the predicted LST data of both testing experiment and fusion experiment can describe the more detailed spatiotemporal variations of the LST in the study area. However, there are still some limitations: (1) the STARFM cannot delineate the difference in the overpassing time between the two sensors, which may lead to uncertainty in the fusion results; (2) the STARFM requires, at least, one pair of input images of different spatial resolution images and free from cloudcontamination. However, due to the limitations of cloudy and rainy weather in the tropical city, it would be difficult to obtain sufficient such images in each season for further UTE study. Therefore, the further studies should propose a new spatiotemporal fusion method for predicting LST data to overcome these limitations. (3) The majority of the previous studies on the UHI have been in large continental cities such as Mexico City or Los Angeles. Recent discovery indicates that the UHI occurs in much of the typical coastal cities throughout the year. However, the driver for UHI development in different climates is different [42], and the effectiveness of solve the UTE degradation method is different from city to city [48]. For example, Keeratikasikorn and Bonafoni [49] provide an overview of the SUHI phenomenon in Bangkok, Thailand; they suggest that mitigating the UHI problem should be integrated into the land use planning of the municipality. Li and Norford [50] evaluate the UHI and the possible mitigation measures of green vegetation and cool roof in a tropical city, Singapore. They found that the deployment of green vegetations and cool roofs could reduce the near-surface air temperature during the night time and daytime, respectively. Therefore, in the next stage, we should comprehensively consider the social driving factors and natural driving factors and propose a consortium of strategies and effective methods for managing UTE problems in Shenzhen.

\section{Conclusions}

This paper uses the STARFM to produce high-spatiotemporal resolution daytime LST by combining MODIS and HJ1B LST data to study the seasonal variations of the daytime UTE in Shenzhen in tropical regions covered by clouds and rainy weather throughout the year. The objective was to examine the seasonal variations of the daytime LST to different land cover types and assess the effects of seasonal variations of high-grade daytime LST using landscape metrics. Several conclusions were made as follows: (1) The predicted seasonal LST products can be used for monitoring the variation of daytime LST in urban thermal environment. (2) During the study period, the distribution of daytime LSTs in Shenzhen showed an increasing trend from east to west, and daytime LSTs were higher in spring and summer than autumn and winter. (3) The highest and lowest daytime LSTs in each season were observed in ISAs and water bodies. (4) Landscape metrics at the class and landscape levels provide a quantitative method that can be used to describe the seasonal variation in the daytime LSTs, while the daytime LSTs in Shenzhen are dominated and fragmented by high-grade daytime LST patches in each season.

\section{Data Availability}

The HJ-1B data used to support the findings of this study are available from the China Centre for Resources Satellite Data and Application (http://www.cresda.com/CN/).

\section{Conflicts of Interest}

The authors declare that there are no conflicts of interest regarding the publication of this paper.

\section{Authors' Contributions}

Yuan Yao designed the research. Yiling Lu, Lulu Liu, and Min Liao processed the data. Yuan Yao and Fang Zhang analyzed the results and wrote the manuscript. All authors contributed to the final version of the manuscript by proofreading and providing constructive ideas.

\section{Acknowledgments}

This study was financially supported by the China National Natural Science Foundation (41761041).

\section{References}

[1] United Nations and World Urbanization Prospects, The 2014 Revision; United Nations Department of Economics and Social Affairs, Population Division, New York, NY, USA, 2015.

[2] W. Leal Filho, L. Echevarria Icaza, A. Neht, M. Klavins, and E. A. Morgan, "Coping with the impacts of urban heat islands. a literature based study on understanding urban heat vulnerability and the need for resilience in cities in a global climate change context," Journal of Cleaner Production, vol. 171, pp. 1140-1149, 2018.

[3] R. C. Estoque, Y. Murayama, and S. W. Myint, "Effects of landscape composition and pattern on land surface temperature: an urban heat island study in the megacities of Southeast Asia," Science of the Total Environment, vol. 577, pp. 349-359, 2017.

[4] J. Peng, P. Xie, Y. Liu, and J. Ma, "Urban thermal environment dynamics and associated landscape pattern factors: a case study in the Beijing metropolitan region," Remote Sensing of Environment, vol. 173, pp. 145-155, 2016.

[5] Y. Xiong, S. Huang, F. Chen, H. Ye, C. Wang, and C. Zhu, "The impacts of rapid urbanization on the thermal environment: a remote sensing study of Guangzhou, South China," Remote Sensing, vol. 4, no. 7, pp. 2033-2056, 2012.

[6] G. Mihalakakou, M. Santamouris, N. Papanikolaou, C. Cartalis, and A. Tsangrassoulis, "Simulation of the urban heat island phenomenon in Mediterranean climates," Pure and Applied Geophysics, vol. 161, no. 2, pp. 429-451, 2004. 
[7] T. Oke, "The energetic basic of the urban heat island," Quarterly Journal of the Royal Meteorological Society, vol. 108, no. 455, pp. 1-24, 1982.

[8] A. Almusaed, "The urban heat island phenomenon upon urban components," in Biophilic and Bioclimatic Architecture, pp. 139-150, Springer, London, UK, 2011.

[9] H. Akbari, Energy Saving Potentials and Air Quality Benefits of Urban Heat Island Mitigation, Lawrence Berkeley National Laboratory, Berkeley, CA, USA, 2005.

[10] M. Agarwal and A. Tandon, "Modeling of the urban heat island in the form of mesoscale wind and of its effect on air pollution dispersal," Applied Mathematical Modelling, vol. 34, no. 9, pp. 2520-2530, 2010.

[11] A. Ferrari, A. Kubilay, D. Derome, and J. Carmeliet, "The use of permeable and reflective pavements as a potential strategy for urban heat island mitigation," Urban Climate, vol. 31, Article ID 100534, 2020.

[12] B.-J. He, "Towards the next generation of green building for urban heat island mitigation: zero UHI impact building," Sustainable Cities and Society, vol. 50, Article ID 101647, 2019.

[13] H. Farhadi, M. Faizi, and H. Sanaieian, "Mitigating the urban heat island in a residential area in Tehran: investigating the role of vegetation, materials, and orientation of buildings," Sustainable Cities and Society, vol. 46, Article ID 101448, 2019.

[14] Y. Lin, Z. Wang, C. Y. Jim, J. Li, J. Deng, and J. Liu, "Water as an urban heat sink: blue infrastructure alleviates urban heat island effect in mega-city agglomeration," Journal of Cleaner Production, vol. 262, Article ID 121411, 2020.

[15] Y. Jamei, P. Rajagopalan, and Q. Sun, "Spatial structure of surface urban heat island and its relationship with vegetation and built-up areas in Melbourne, Australia," Science of the Total Environment, vol. 659, pp. 1335-1351, 2019.

[16] J. C. Jiménez-Muñoz and J. A. Sobrino, "A generalized singlechannel method for retrieving land surface temperature from remote sensing data," Journal of Geophysical Research: Atmospheres, vol. 108, 2003.

[17] Z. Qin, A. Karnieli, and P. Berliner, "A mono-window algorithm for retrieving land surface temperature from Landsat TM data and its application to the Israel-Egypt border region," International Journal of Remote Sensing, vol. 22, no. 18, pp. 3719-3746, 2001.

[18] F. Becker and Z.-L. Li, "Towards a local split window method over land surfaces," International Journal of Remote Sensing, vol. 11, no. 3, pp. 369-393, 1990.

[19] A. Sekertekin and S. Bonafoni, "Land surface temperature retrieval from Landsat 5, 7, and 8 over rural areas: assessment of different retrieval algorithms and emissivity models and toolbox implementation," Remote Sensing, vol. 12, no. 2, p. 294, 2020.

[20] X. Yu, X. Guo, and Z. Wu, "Land surface temperature retrieval from landsat 8 TIRS-comparison between radiative transfer equation-based method, split window algorithm and single channel method," Remote Sensing, vol. 6, no. 10, pp. 9829-9852, 2014.

[21] Y. Chen, X. Li, X. Liu, and B. Ai, "Analyzing land-cover change and corresponding impacts on carbon budget in a fast developing sub-tropical region by integrating MODIS and Landsat TM/ETM+ images," Applied Geography, vol. 45, pp. 10-21, 2013.

[22] S.-B. Duan, Z.-L. Li, H. Li et al., "Validation of collection 6 MODIS land surface temperature product using in situ measurements," Remote Sensing of Environment, vol. 225, pp. 16-29, 2019.
[23] J. Wang, B. Huang, D. Fu, and P. Atkinson, "Spatiotemporal variation in surface urban heat island intensity and associated determinants across major Chinese cities," Remote Sensing, vol. 7, no. 4, pp. 3670-3689, 2015.

[24] P. Wu, H. Shen, L. Zhang, and F.-M. Göttsche, "Integrated fusion of multi-scale polar-orbiting and geostationary satellite observations for the mapping of high spatial and temporal resolution land surface temperature," Remote Sensing of Environment, vol. 156, pp. 169-181, 2015.

[25] X. Zhu, E. H. Helmer, F. Gao, D. Liu, J. Chen, and M. A. Lefsky, "A flexible spatiotemporal method for fusing satellite images with different resolutions," Remote Sensing of Environment, vol. 172, pp. 165-177, 2016.

[26] Y. Bai, M. Wong, W.-Z. Shi, L.-X. Wu, and K. Qin, “Advancing of land surface temperature retrieval using extreme learning machine and spatio-temporal adaptive data fusion algorithm," Remote Sensing, vol. 7, no. 4, pp. 4424-4441, 2015.

[27] F. Gao, J. Masek, M. Schwaller, and F. Hall, "On the blending of the Landsat and MODIS surface reflectance: predicting daily landsat surface reflectance," IEEE Transactions on Geoscience and Remote Sensing, vol. 44, pp. 2207-2218, 2006.

[28] H. Liu and Q. Weng, "Enhancing temporal resolution of satellite imagery for public health studies: a case study of West Nile Virus outbreak in Los Angeles in 2007," Remote Sensing of Environment, vol. 117, pp. 57-71, 2012.

[29] B. Huang, J. Wang, H. Song, D. Fu, and K. Wong, "Generating high spatiotemporal resolution land surface temperature for urban heat island monitoring," IEEE Geoscience and Remote Sensing Letters, vol. 10, pp. 1011-1015, 2013.

[30] L. Lin, Y. Meng, A. Yue et al., "A spatio-temporal model for forest fire detection using HJ-IRS satellite data," Remote Sensing, vol. 8, no. 5, p. 403, 2016.

[31] "Shenzhen climate overview and seasonal characteristics," 2018, http://www.szmb.gov.cn/mobile/qixiangfuwu/ qihoufuwu/qihouguanceyupinggu/qihougaikuang/.

[32] B. Chen, Z. Wu, J. Wang et al., "Spatio-temporal prediction of leaf area index of rubber plantation using HJ-1A/1B CCD images and recurrent neural network," ISPRS Journal of Photogrammetry and Remote Sensing, vol. 102, pp. 148-160, 2015.

[33] G. Chander, B. L. Markham, and D. L. Helder, "Summary of current radiometric calibration coefficients for Landsat MSS, TM, ETM+, and EO-1 ALI sensors," Remote Sensing of Environment, vol. 113, no. 5, pp. 893-903, 2009.

[34] S. Peng, S. Piao, P. Ciais et al., "Surface urban heat island across 419 global big cities," Environmental Science \& Technology, vol. 46, no. 2, pp. 696-703, 2012.

[35] Z. Wan and J. Dozier, "A generalized split-window algorithm for retrieving land-surface temperature from space," IEEE Transactions on Geoscience and Remote Sensing, vol. 34, pp. 892-905, 1996.

[36] D. Alexakis and I. Tsanis, "Comparison of multiple linear regression and artificial neural network models for downscaling TRMM precipitation products using MODIS data," Environmental Earth Sciences, vol. 75, pp. 1-13, 2016.

[37] H. Xu, F. Ding, and X. Wen, "Urban expansion and heat island dynamics in the Quanzhou region, China," IEEE Journal of Selected Topics in Applied Earth Observations and Remote Sensing, vol. 2, no. 2, pp. 74-79, 2009.

[38] Y. Zhang, H. Balzter, C. Zou, H. Xu, and F. Tang, "Characterizing bi-temporal patterns of land surface temperature using landscape metrics based on sub-pixel classifications from Landsat TM/ETM+," International Journal of Applied 
Earth Observation and Geoinformation, vol. 42, pp. 87-96, 2015.

[39] H. Liu and Q. Weng, "Seasonal variations in the relationship between landscape pattern and land surface temperature in Indianapolis, USA," Environmental Monitoring and Assessment, vol. 144, no. 1-3, pp. 199-219, 2008.

[40] H. Li and J. Wu, "Use and misuse of landscape indices," Landscape Ecology, vol. 19, no. 4, pp. 389-399, 2004.

[41] D. Zhou, S. Zhao, S. Liu, L. Zhang, and C. Zhu, "Surface urban heat island in China's 32 major cities: spatial patterns and drivers," Remote Sensing of Environment, vol. 152, pp. 51-61, 2014.

[42] L. Zhao, X. Lee, R. B. Smith, and K. Oleson, "Strong contributions of local background climate to urban heat is," Nature, vol. 511, no. 7508, p. 216, 2014.

[43] D. Zhou, L. Zhang, D. Li, D. Huang, and C. Zhu, "Climate-vegetation control on the diurnal and seasonal variations of surface urban heat islands in China," Environmental Research Letters, vol. 11, Article ID 074009, 2016.

[44] R. A. Memon, D. Y. C. Leung, and C.-H. Liu, "Effects of building aspect ratio and wind speed on air temperatures in urban-like street canyons," Building and Environment, vol. 45, no. 1, pp. 176-188, 2010.

[45] P. Rajagopalan, K. C. Lim, and E. Jamei, "Urban heat island and wind flow characteristics of a tropical city," Solar Energy, vol. 107, pp. 159-170, 2014

[46] J. Li, C. Song, L. Cao, F. Zhu, X. Meng, and J. Wu, "Impacts of landscape structure on surface urban heat islands: a case study of Shanghai, China," Remote Sensing of Environment, vol. 115, no. 12, pp. 3249-3263, 2011.

[47] E. Morini, B. Castellani, A. Presciutti, M. Filipponi, A. Nicolini, and F. Rossi, "Optic-energy performance improvement of exterior paints for buildings," Energy and Buildings, vol. 139, pp. 690-701, 2017.

[48] D. Li, E. Bou-Zeid, and M. Oppenheimer, "The effectiveness of cool and green roofs as urban heat island mitigation strategies," Environmental Research Letters, vol. 9, no. 5, p. 055002 , 2014.

[49] C. Keeratikasikorn and S. Bonafoni, "Urban heat island analysis over the land use zoning plan of bangkok by means of landsat 8 imagery," Remote Sensing, vol. 10, no. 3, p. 440, 2018.

[50] X.-X. Li and L. K. Norford, "Evaluation of cool roof and vegetations in mitigating urban heat island in a tropical city, Singapore," Urban Climate, vol. 16, pp. 59-74, 2016. 